C00-1198-1128

THE SOLUBILITY OF HYDROGEN IN TANTALUM

Philippe Lecocq

Department of Metallurgical Engineering

and Materials Research Laboratory

University of Illinois, Urbana, Illinois 61801

October 1974

This technical information document is based on a thesis submitted in partial fulfillment of the requirements for the degree of Doctor of Philosophy in Metallurgical Engineering in the Graduate College of the University of Illinois, 1974. This research was supported in part by the U. S. Atomic Energy Commission under Contract AT(11-1)-1198. 


\section{DISCLAIMER}

This report was prepared as an account of work sponsored by an agency of the United States Government. Neither the United States Government nor any agency Thereof, nor any of their employees, makes any warranty, express or implied, or assumes any legal liability or responsibility for the accuracy, completeness, or usefulness of any information, apparatus, product, or process disclosed, or represents that its use would not infringe privately owned rights. Reference herein to any specific commercial product, process, or service by trade name, trademark, manufacturer, or otherwise does not necessarily constitute or imply its endorsement, recommendation, or favoring by the United States Government or any agency thereof. The views and opinions of authors expressed herein do not necessarily state or reflect those of the United States Government or any agency thereof. 


\section{DISCLAIMER}

Portions of this document may be illegible in electronic image products. Images are produced from the best available original document. 
$31^{2000}$

\title{
THE SOLUBILITY OF HYDROGEN IN TANTALUM
}

\author{
Philippe Lecocq \\ Department of Metallurgy and Mining Engineering \\ University of Illinois at Urbana-Champaign, 1974
}

The solubility of hydrogen in tantalum in equilibrium with the hydride has been measured by a resistometric technique. Alloys ranged in composition from 0.5 to 10 at.\% H. The solvus Iine is given by the equation $\ln C=6.0-2150 / R T$. The heat of solution of $2150 \mathrm{cal} / \mathrm{mole}$ is lower than that for $\mathrm{Nb}(2750 \mathrm{cal} /$ mole) and $\mathrm{V}(3900 \mathrm{cal} / \mathrm{mole})$. Ternary Ta-0-H alloys (containing 0.6 at.\% oxygen in solid solution) had a solvus line for hydrogen no different from the Ta-H binary system, a behavior similar to that of the $\mathrm{Nb}-\mathrm{H}$ system. The Ta-D solvus is closely the same as that for hydrogen in tantalum. Thermal cycling up and down through the solvus temperature increases the. "apparent" solvus temperature slightly (a few ${ }^{\circ} \mathrm{K}$ ). A thermal hysteresis occurs on cooling and heating, a hysteresis explained in terms of mechanical constraint of the matrix on the nucleation and growth of the precipitate. Growth of the hydrides depends on long-range diffusion. Trapping of hydrogen by oxygen is believed to be responsible for low diffusivities and the long times needed to achieve equilibrium. The contribution of hydrogen and deuterium in solid solution to the residual resistivity of tantalum is $0.51 \mu \Omega$ cm per at.\%, a value lower than that for either vanadium and nioblum. 
THIS PAGE

\section{WAS INTENTIONALLY LEFT BLANK}




\section{> ACKNOWLEDGEMENTS}

The author gratefully acknowledges the constant support, guidance and help given by his advisor, Professor Charles A. Wert. Thanks are owed to Dr. D. Westlake for helpful discussions and comments as well as for providing pertinent diagrams and results of an unpublished work. The author is grateful to his wife, Michele, for her patience, understanding and assistance during the course and preparation of this thesis. Finally, the author wishes to dedicate this thesis to his wife and his son, Bertrand.

This research was supported in part by the United States Atomic Energy Commission under contract AT(11-1)-1198 and the Department of Metallurgy and Minfng Engineering. 
THIS PAGE

WAS INTENTIONALLY

LEFT BLANK 


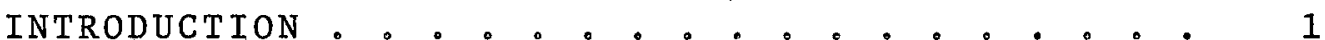

The Ta-H Alloy System.......... . . 1

The V-H Alloy system. . . . . . . . . 3

The $\mathrm{Nb}-\mathrm{H}$ Alloy System......... . . 4

Summary of the $\mathrm{Ta}-\mathrm{H}$, the $\mathrm{V}-\mathrm{H}$ and the $\mathrm{Nb}-\mathrm{H}$

observations . . . . . . . . . . 6

The Meta1-Deuterium Systems..... . . 9

Summary . . . . . . . . . . . . . 10

EXPERIMENTAL PROCEDURE • . . . . . . . . . . . . 11

Specimen Preparation . . . . . . . . . 11

Resistivity Measurements . . . . . . . . 13

EXPERIMENTAL RESULTS • • . . . . . . . . . 15

Hydrogen Solubility in Pure Tantalum . . . 15

Hydrogen Solubility in Oxygen-Doped

Tantalum . . . . . . . . . . . . 20

Deuterium Solubility in Pure Tantalum . . 21

Influence of the Cooling Rate...... . 22

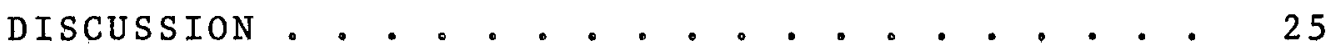

CONCLUSIONS

APPENDIX . . . . . . . . . . . . . 77

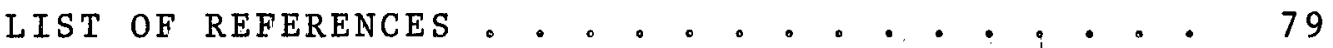

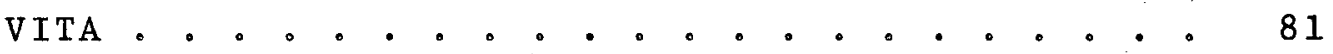


INTRODUCTION

\begin{abstract}
Alloys of hydrogen in the metals have been extensively investigated in recent years not only because of their technological importance, but also because of their intellectual interest. Some of the metals absorb a relatively small amount of hydrogen and do not form hydrides; among these are copper, nickel, gold, silver, and iron. Other metals of structural importance such as vanadium, niobium, tantalum, and titanium have large solubility for hydrogen in the solid state and readily form hydrides at low temperature. For some of these systems, the solubility has been determined rather conclusively, but for others, considerable discrepancy exists between various studies. The Ta-H system is one showing great variability, so this study was undertaken to examine these differences, After a brief introduction into the general features of the bcc systems with hydrogen, a more detailed statement will be made about the goals of the work.
\end{abstract}

The Ta-H Alloy System

The general features of the tantalum-hydrogen system at low temperatures have been worked out by Ducastelle, Caudron, and Costa using $x$-ray and resistivity measurements. ${ }^{1}$ The phase diagram which they draw is shown in Figure 1. Above $300^{\circ} \mathrm{K}$ an $\alpha$ solid solution exists in which hydrogen is soluble 
nearly to a $1 / 1$ ratio. Below that temperature the phase diagram is controlled by the $\beta$ phase, $\mathrm{Ta}{ }_{2} \mathrm{H}$, which exists over a reasonably wide temperature range below room temperature. The low-composition side of the $\beta$ phase was first worked out by Waite, Wallace, and Craig much earlier; ${ }^{2}$ their work is in reasonably good accord with the later work shown in Figure 1. In addition, Waite et a1. had determined the solvus line showing equilibrium between the $\alpha$ phase and the $\beta$ phase below room temperature using specific heat measurements. other investigators, using a variety of physical measurements a1so made determinations of the solvus line. Measurements of anomalies in the heat capacity curve were used by kelley. ${ }^{3}$ An internal friction effect which occurs with the formation of hydrides during cooling was used by Cannel11 and Mazzolai. 4 A magnetic resonance technique using the proton resonance was used by Pedersen, Krogdah1, and Stokkeland. 5 optical observations of hydride precipitation and dissolution were used by Owen and Scott。 6 They also used a macroscopic shape change related to hydride precipitation -- a technique they termed the "Poynting Method." Recent1y other observations based on resistivity methods were published by Matsuyama, Dohi and Hisano. 7 Finally, a thermo-chemical method was used by Veleckis and Edwards. 8 Many of these results show good selfconsistency, but some are at wide variance with others. Many 
of the data just described are plotted in Figure 2. The wide variation of the reported solvus lines is evident. One of the goals of the present work was to examine this solvus line in detail using electrical resistivity measurements and taking great precautions to ascertain that the system was in reasonable equilibrium at al1 times.

The V-H Alloy System

Alloys of hydrogen with vanadium have been examined much more extensively than the tantalum hydrogen system. The phase diagram is also controlled at low temperatures by a hydride $\mathrm{V}_{2} \mathrm{H}$. Again, the metal absorbs a large concentration of hydrogen at high temperatures, and the solid solution is in equilibrium with the hydride at lower temperatures. The solvus line has also been investigated extensively by a number of experimental techniques. Electrical resistivity measurements were used by Westlake ${ }^{9}$ and by Chang. 10 An internal friction technique was used by Chang and Wert, 11 by Owen and Scott, 6 and by Cannelli and Mazzolai.12 Owen and Scott also used their "poynting" method and visual observations. All of these results are in fairly good agreement, as the data in Figure 3 show, but some systematic differences clearly exist. These differences were shown by Chang and Wert probably to be caused by differences in oxygen concentration of alloys used by the various investigators. ${ }^{11}$ 
A systematic study of the role of oxygen, nitrogen, and carbon on the solvus line for hydrogen in vanadium was a part of the study of Chang and Wert. Their results for oxygendoped material are summarized in Figure 4, together with some of the results of the other investigators. A quantitative thermodynamic analysis was given by Chang and Wert based on the supposition that clusters of hydrogen with individual oxygen, nitrogen, or carbon atoms affect the equilibrium between the $\alpha$ phase and the hydride $V_{2} H$. Their analysis showed that the most predominant clusters for carbon and nitrogen were the pairs $\mathrm{C}-\mathrm{H}$, and $\mathrm{N}-\mathrm{H}$, but that higher order clusters of composition around $0-H^{3}$ were the most common for specimens containing oxygen. Whether this interpretation is precisely correct, there is no doubt that the presence of the immobile interstitials such as oxygen, nitrogen, and carbon can greatiy affect the observed solvus temperature.

The $\mathrm{Nb}-\mathrm{H}$ System

Alloys of hydrogen with niobium also show large solubility above room temperature. For this system, however, the equilibrium of the $\alpha$ solid solution is not with the type of hydride found in tantalum and vanadium. Rather in this case, the hydride is the monohydride $\mathrm{NbH}$. The solvus ine has been Investigated by many experimenters. X-ray diffraction and thermo- 
analysis were employed by Walter and Chandler to study many aspects of the phase diagram.13 Internal friction methods have been used by Thompson, Buck and Wert, ${ }^{14}$ and by. Baker and Birnbaum. 15 Electrical resistivity measurements were used by Westlake, ${ }^{16}$ by Westlake and ockers, ${ }^{17}$ and by Holmquist ${ }^{18}$ to study the low temperature part of the solvus line. These results are only in fair agreement with each other and the origin of the discrepancies which exist are not well understood. Although the different experimenters undoubtedly had different levels of oxygen impurity, no systematic features have been identified which show that the equilibrium between the $\alpha$ and $\beta$ phases is affected by the presence of oxygen. In fact, the data of Westlake 16 and of Westlake and ockers, 17 shown in Figure 5, tend to prove that oxygen has no effect on the solvus line.

One of the striking features of the $\mathrm{Nb}-\mathrm{H}$ system is the hysteresis which accompanies cooling and heating through the temperature region around the solvus temperature for a given composition. A typical example of this hysteresis is shown from the thesis of Holmquist, see Figure 6. During the first.cooling, precipitation starts at temperature $T_{I}(I)$, and the hydride begins to redissolve at a temperature $\mathrm{T}_{2}$ (1) on heating. Heating and cooling curves coincide only at higher temperatures greater than some temperature $\mathrm{T}_{3}$. During successive thermal cycles, Holmquist ${ }^{18}$ found that the hysteresis loop tended to close somewhat, but some hysteresis always remained. Similar 
hysteresis effects were observed by Westlake ${ }^{16}$ for this system; Westlake has found that extremely slow cooling rates are. required, especially for low hydrogen concentrations, to ensure that reasonable thermal equilibrium is achieved at all temperatures. Suppositions about the origin of this thermo-hysteresis will be described in a later paragraph.

Summary of the $\mathrm{Ta}-\mathrm{H}$, the $\mathrm{V}-\mathrm{H}$ and the $\mathrm{Nb}-\mathrm{H}$ Observations

The observations described for these three alloy systems show several major features. First, a wide variety of experimental methods can be used to detect the onset of precipitation during cooling of a solid solution. These results give generally fair agreement with each other, but differences between different investigators are far outside the internal consistency of individual studies. These may be due to unknown differences in the chemistry of the alloys, to the effects of unknown quantities of impurities, or to the lack of establishment of thermal equilibrium in individual cases.

The second striking effect is the existence of large hysteresis between observations made during cooling and heating through the solvus temperature. Vanadium shows almost no hysteresis, but both nioblum and tantalum are found to exhibit this effect. Its explanation has generally been thought to lie in the large amount of internal plastic deformation which accompanies the formation of hydrides in these metals. The 
metal hydride is about $10 \%$ less dense than the metal matrix and part of the resulting strain is taken up by generation of dislocations in the matrix when the hydride precipitates form. These dislocations have been strikingly observed by schober ${ }^{19}$ in niobium during precipitation of fine scale hydrides at low temperatures and by $\mathrm{Chang}^{10}$ in precipitation of hugie plates of vanadium hydrides at much higher concentrations near room temperature. These dislocations have also been observed in the titanium-hydrogen system by Paton, Hickman, and Les1ie. 20 A theory to explain the effects of the surrounding matrix on a hydride plate which nucleates and grows has been proposed by Paton et al. They proposed that the normal free energy change which would accompany the formation of massive unrestrained hydrides is modified by elastic and plastic contributions to the enthalpies. The hysteresis of the cooling and heating cycle could be explained on the inability of the system to reabsorb all of the dislocations punched out by the precipitates as they form upon cooling. Paton and co-workers initially developed this theory to explain large changes in apparent solubility of hydrogen in titanium which accompanied the addition of aluminum. They proposed that the aluminum modified the ability of the hydrides to punch out dislocations and thus modified the apparent solvus temperature. The same argument could apply to the systems with tantalum, vanadium, or niobium if alloy elements such as oxygen, carbon, or nitrogen 
commonly found in these systems were also to alter the ability of the matrix to resist plastic deformation. No detailed theory of this effect has yet been published for the systems, however.

The role of the immobile interstitials such as oxygen may indeed simply be to strengthen the matrix, but the ability of interstitials to form immobile clusters and thus alter the thermodynamic equilibrium is an attractive possibility. The existence of clusters of $\mathrm{N}-\mathrm{H}$ and $\mathrm{O}-\mathrm{H}$ as well as $\mathrm{H}-\mathrm{H}$ pairs in niobium has been amply demonstrated by Baker and Birnbaum. 15 They found that hydrogen could presumably not exist as single $\mathrm{H}$ atoms as long as oxygen or nitrogen atoms were around to trap them; the binding energy of 0.1 ev measured for these systems is much larger than $\mathrm{kT}$ at low temperatures and thermodynamic equilibrium would be much in favor of formation of clusters until the oxygen or nftrogen atoms were saturated. Since the enthalpies of solution of the hydrides are also around 0.1 to $0.2 \mathrm{ev}$, the thermodynamic balance is a very delicate one; and, the determination of the probable role of oxygen, nitrogen, or carbon is not an easy one. At the very least, it is clear that this trapping is strong enough to alter appreciably the diffusion rate of hydrogen; hence, extremely slow cooling and heating rates are required to ensure the establishment of equilibrium at all temperatures. The possibility that hydrogen could be trapped by lattice defects 
has also been pointed out by oriani in his analysis of data on diffusion of hydrogen in iron and steel. 21

The present investigation also had the goal of determining the solvus line in tantalum which had been degassed of nitrogen and oxygen. In particular, the role of oxygen in affecting the equilibrium solvus line and the rate of approach to equilibrium was to be studied in detail.

\section{The Meta1-Deuterium Systems}

Inconsistencies exist between the several metals concerning the effect of differences in isotopic mass on the phase equilibrium. In vanadium, the solvus line for deuterium has been determined by Westlake and ockers ${ }^{2}$ using resistivity methods and by Cannel1i and Mazzolai ${ }^{23}$ using internal friction techniques. The results of these two investigations agree quite well and show that deuterium is about twice as soluble as hydrogen in vanadium at a given temperature, although the heat of solutions is roughly the same. In niobium, Holmquist ${ }^{18}$ and Westlake and ockers ${ }^{17}$ have found no isotope effect upon addition of hydrogen and of deuterium to that metal, Figure 5. The two reported measurements for tantalum are conflicting. Pryde and Tsong have found no isotope effect on the solvus In tantalum from equilibrium pressure and electrical resistance measurements. 24 on the other hand, Cannelli and Cantel1i have found, for lower concentrations, a distinct difference in the 
solvus between hydrogen and deuterium using internal friction measurements, Figure 7. Again, they found deuterium to be more soluble than hydrogen. An additional goal of the present investigation was to verify the one or the other of these observations.

\section{$\underline{\text { Summary }}$}

This investigation thus had the following goals:

1. To establish the solubility limit in oxygen-free tantalum as a function of temperature.

2. To investigate the general features of hysteresis of hydride formation and dissolution in this system.

3. To investigate the effect of oxygen on the solvus Iine.

4. To ascertain whether or not the Ta-H solvus is the same as that for Ta-D。 


\section{EXPERIMENTAL PROCEDURE}

\section{Specimen Preparation}

The tantalum was Materials Research Corporation rods of marz grade purity. The chemical analysis furnished by the supplier is given in Table I. After cleaning in a solution $\mathrm{HF}: \mathrm{HNO}_{3}: \mathrm{H}_{2} \mathrm{O}$, the $1 / 4$ inch rods were swaged to $45 \mathrm{mil}$. wires. They were then cold-rolled to 10 mil foils and cleaned. Strips of foils were annealed in vacuum at $2400^{\circ} \mathrm{C}$ for 4 to 5 hours typically. The foils were heated during this treatment by the joule heat of a dc current in a vacuum better than $5 \times 10^{-7}$ torr. The recrystallized foils had a typical grain size of $1 / 2$ to $1 \mathrm{~mm}$ in diameter.

The gases hydrogen, deuterium and oxygen were of research purity grade. Specimens containing only hydrogen, or deuterium were prepared by reacting the foils with known amounts of gas introduced at $1300^{\circ} \mathrm{C}$. The temperature was then slowly decreased and the absorption of the gas by the foils was followed by the decrease in gas pressure. When the pressure reached $0.1 \%$ of the initial value, the foils were cooled to room temperature.

specimens containing both oxygen and hydrogen were prepared in two steps. Oxygen was first added by reacting the foils with a known quantity of gas at $1500^{\circ} \mathrm{C}$ for 1 hour. The foils were then radiation cooled to room temperature and 
Table I。 Supplier's Analysis of Tantalum Starting Material (A11 values are in weight ppm.)

$\begin{array}{lr}0 & 8.0 \\ \mathrm{~N} & 2.0 \\ \mathrm{C} & 10.0 \\ \mathrm{Na} & 0.1 \\ \mathrm{Mg} & 0.2 \\ \mathrm{Al} & 0.2 \\ \mathrm{Si} & 0.3 \\ \mathrm{P} & 0.2 \\ \mathrm{~S} & 0.6 \\ \mathrm{C} 1 & 0.6 \\ \mathrm{~K} & 0.01 \\ \mathrm{Ca} & 0.3 \\ \mathrm{~V} & 0.1\end{array}$

$\begin{array}{lr}\mathrm{Cr} & 0.1 \\ \mathrm{Mn} & 0.03 \\ \mathrm{Fe} & 1.0 \\ \mathrm{Cu} & 0.2 \\ \mathrm{Zn} & 0.5 \\ \mathrm{Se} & <1.0 \\ \mathrm{Nb} & 5.0 \\ \mathrm{Te} & <2.0 \\ \mathrm{~W} & 10.0 \\ \mathrm{Pt} & <1.0 \\ \mathrm{Au} & <2.0 \\ \mathrm{Th} & <0.3 \\ \mathrm{U} & <0.4\end{array}$

All others non-detected to $0.1 \mathrm{ppm}$ 
the vacuum was brought back to a value better than $5 \times 10^{-7}$ torf. They were then reheated to $1300^{\circ} \mathrm{C}$ and a known volume of hydrogen was introduced. The regular procedure was then followed. However in this case the reaction was sluggish and a certain amount of hydrogen was not absorbed. The difference between the initial and final pressure readings was used to calculate the exact amount of hydrogen absorbed.

Since the solubility of oxygen in tantalum is not well known at room temperature, the assumption of an oxygen solid solution had to be verified. A sample containing $6000 \mathrm{ppm}$ oxygen was prepared and cooled to room temperature at a rate four times slower than the typical rate used during subsequent hydrogen doping. The sample was then thinned and observed in the electron microscope. No trace of a second phase was found.

Resistivity Measurements

The classical four lead method was used. Current and potential leads made of outgassed Ta wire were spotwelded on a 5 inch foil. Temperatures were measured by two copperconstantan thermocouples spotwelded on the top and bottom of the specimens outside the potential leads. Two windings around copper cylinders in which the specimens were mounted permitted adjustment of cooling and heating rates by joule effect. This setup permitted constancy of temperature along the foil to less than $1^{\circ} \mathrm{K}$ between the two extremities of the 
specimens. A current of about 0.5 ampere was supplied by a 6 volt battery. The voltage drop across a known resistance $(0.100 \Omega)$ and across the sample was measured on a digital voltmeter with a sensitivity of $1 \mu v$. 


\section{EXPERIMENTAL RESULTS}

\section{Hydrogen Solubility in Pure Tantalum}

The compositions of hydrogen used in the present experiment were in the range 0.5 at.\% to 10 at.\%. The solvus temperatures for this range of compositions were expected to 1 fe between $175^{\circ} \mathrm{K}$ and $300^{\circ} \mathrm{K}$. Therefore, an inftial measurement was made for a purified specimen containing no hydrogen to determine the shape of the curve of resistance as a function of the temperature. Data obtained on cooling and heating are drawn in Figure 8. As can be seen, no hysteresis is observed on cooling and heating. The curve, nearly a straight ine, is slightly concave downward since the Debye temperature for pure tantalum $1 \mathrm{~s}$ about $240^{\circ} \mathrm{K} .{ }^{1}$ Th1s temperature increases with hydrogen content, however in the following, cooling curves of solid solutions are approximated as stxalght lines within experimental error. The data points plotted in Figure 8 are only about one-half of the data obtained in this run; the rest have been omitted for purposes of clarity in drawing the line. The same procedure 18 adopted for almilax curves reported in this section.

Measuremente of the solvus temperature were made for six compostiono spaced over the range. In the early stagea of the experiment, the temperature was reduced at a modest rate, about $1^{\circ} \mathrm{K}$ per minute. Numerous observations were made 
which could not be easily interpreted in terms of a simple solvus line. During the course of the investigation, the results of the experiments of Westlake and ockers on niobium became available, and the possibility of too-rapid cooling became apparent. 17 Consequently, a second set of observations were made in which the cooling rate was extremely low, about $2^{\circ} \mathrm{K}$ per hour. This cooling rate gave quite different results from the early observations and are internally consistent among the specimens. A measurement for the specimen containing 1.5 at.$\% \mathrm{H}$ is shown in. Figure 9. During the fixst cooling, the resistance decreases linearly with the temperature until a temperature $\mathrm{T}_{1}(1)$ is reached. Below that temperature, the resistance decreases linearly but with a steeper temperature dependence. At a temperature of $160^{\circ} \mathrm{K}$ cooling is stopped and the temperature is slowly raised. The resistance increase upon warming is also approximately linear with temperature until some temperature $\mathrm{T}_{2}(1)$ is reached; then the line becomes steeper and remains nearly linear to some temperature $T_{3}$ where it intersects the first cooling line. The resistance then retraces the cooling 1ine to room temperature. A second cooling shows the same hysteresis, but in this instance, the temperature $\mathrm{T}_{1}$ is a few degrees higher. Thus, the steeper part of the cooling curve is shifted about $2^{\circ}$ or $3^{\circ}$ higher in temperature. The heating curve on the second cycle is identical to that on the first cycle. Successive cycling shows 
cooling and heating curves indistinguishable from the second cycle. Thus, we have several temperatures of interest. Temperature $T_{1}(1)$ is considered to be the temperature of formation of the fixst hydride precipitate for this composition. During the cooling below $T_{1}$ the hydride forms continuously. After turning around at $160^{\circ} \mathrm{K}$, the hydride must begin to dissolve; but, the dissolution is not complete until the temperature $\mathrm{T}_{3}$ is reached. The significance of temperature $\mathrm{T}_{2}$ seems not certain and is discussed later. The temperature $T_{1}$ (2) on the second cooling is considered to be the precipitation temperature for formation of hydride in the presence of residual dislocations presumed to be punched out during the first cooling.

The existence of hysteresis makes one wonder whether or not the cooling and heating rates of $2^{\circ} \mathrm{K}$ per hour are slow enough for this composition. Consequently, several types of investigations were made to check this point. During the fixst cooling, a specimen was held at a temperature slightly below $\mathrm{T}_{1}(1)$ for twelve hours. The resistance remained constant during this constant temperature anneal. Furthermore, the resistance remained constant on the first heating at a temperature of $201^{\circ} \mathrm{K}$ - this is slightly above $\mathrm{T}_{1}$ (I) - for an anneal of eight hours. Thus, it is assumed that a resistance reading is characteristic of the temperature with the cooling and heating rates used. For this specimen and other specimens 
the temperature $\mathrm{T}_{1}(1)$ is considered to be the "solvus temperature."

A similar set of observations was obtained for a specimen containing 4 at.\% $\mathrm{H}$; the results are summarized in Figure 10 . On the first cooling a linear temperature dependence of the resistance is found until the temperature $T_{1}(1)$ is reached. Below that temperature the curve for this alloy is not straight but is convex upward. The heating curve does not retrace the cooling curve but again shows a hysteresis; in this instance without any breaks until $T_{3}$ is reached. Above that temperature the resistance line retraces the original cooling line. On the second cooling the onset of precipitation occurs at some temperature $T_{1}$ (2) higher than the first. Below that temperature the cooling curve lies under the first, but approaches the line for the first curve as the temperature falls below $150^{\circ} \mathrm{K}$. Again, the heating curve retraces the first. To show the result of continued cycling, this sample was then cycled seven times between $77^{\circ} \mathrm{K}$ and $293^{\circ} \mathrm{K}$ by immersing it successively into a dewar of liquid nitrogen. A cooling curve was then made on the tenth cycle; in this instance, precipitation started at a temperature $\mathrm{T}_{1}(10)$ which was only $2{ }^{\circ} \mathrm{K}$ higher than on the second cooling. Thus, for this specimen the difference between one and ten cycles is not more than $5^{\circ} \mathrm{K}$. The changes in slopes of the cooling curves for more dilute alloys are much smalier and the temperature of precipita- 
tion cannot be read with good precision. However, if the data are plotted as $\Delta \rho$ vs. temperature, the curves show a sharp break. The value. $\Delta p$ is defined by the equation

$$
\Delta \rho=\rho_{\mathrm{Ta}-\mathrm{H}^{-}} \rho_{\mathrm{T} \mathrm{a}}
$$

where $\rho_{\mathrm{Ta}-\mathrm{H}}$ and $\rho_{\mathrm{Ta}}$ are respectively the resistivities of the $\mathrm{Ta}-\mathrm{H}$ alloy and the pure metal. The validity of such a plot is discussed in the appendix. A plot is shown for an alloy of 0.5 at.\% $\mathrm{H}$ in Figure 11. The temperature $\mathrm{T}_{1}$ (I) for this composition can easily be found by extrapolating the two straight lines to a point of intersection. The value of $\mathrm{T}_{1}$ can be read off this plot to about $1^{\circ} \mathrm{K}$. of course, for such a dilute alloy one must be especially careful that the cooling rate be slow enough so that equilibrium is reached at all temperatures. This is difficult to assure with certainty, but the data, when plotted altogether, show that the value of $T_{1}$ for this alloy fits nicely with those at higher composition where supercooling is not thought to be a problem. Therefore, the cooling rate of $2^{\circ} \mathrm{K}$ per hour seems adequate for this alloy as well. Measurements of resistance as a function of temperature have been made for three other alloys at 2,3 , and 10 at.\% The values of $T_{1}$ for these alloys as well as for the three just described are plotted in Figure 12. Also plotted there are the lines from several of the previous investigations. Clearly, the present results agree well with those of Cannelli and Mazzola1 4 and of Walte, Wallace, and Craig。 2 The present 
results disagree markedly from those obtained by owen and Scott. 6 The same data plotted as in Arrhenius' plot shows the present data to fit a nice straight line, Figure 13. The equation of that line is the following:

$$
\operatorname{lnc}(\mathrm{at} . \%)=6.04( \pm 0.014)-\frac{2150( \pm 60)}{\mathrm{RT}} \text {. }
$$

We thus assume that the solvus Iine obeys an exponential with an enthalpy of solution of $2150 \mathrm{cal} / \mathrm{mole}$.

\section{Hydrogen Solubility in Oxygen-Doped Tantalum}

The effect of dissolved oxygen on the temperature of the solvus line was examined for two compositions of hydrogen. The alloys contained 6000 at. ppm oxygen in solid solution. The hydrogen concentrations were 0.63 at. $\% \mathrm{H}(6300$ ato ppm) and 2.62 at. $\%$ H $(26,200$ at. ppm). For these specimens great care was taken to make sure that the cooling rate was slow enough to ensure equilibrium at all temperatures. The samples were slowly cooled at a rate of $12^{\circ} \mathrm{K}$ per hour to a temperature about $10^{\circ} \mathrm{K}$ above the temperature $\mathrm{T}_{1}$ expected for a $\mathrm{Ta}-\mathrm{H}$ alloy of the same composition. Specimens were then cooled in steps of $2^{\circ} \mathrm{K}$ and held at each temperature until the resistance reached a constant value. The cooling rate never exceeded $2^{\circ} \mathrm{K}$ per hour in the $10^{\circ} \mathrm{K}$ interval above the esrimated $\mathrm{T}_{1}$. Below the break-point $T_{1}$ measured for the two alloys, the time needed to reach equilibrium was much longer; for the alloy of 2.62 at. $\%$, the time was 6 hours for temperatures s11ght 1 y below 
$\mathrm{T}_{1}$ and for the alloy containing 0.63 at.\% $\mathrm{H}$ the time was about 40 hours. Because of the long time involved in reaching equilibrium at lower temperatures, the complete hysteresis loop was not measured; only the cooling curves were measured in the vicinity of $\mathrm{T}_{1}$. The cooling curve for the alloy containing $6000 \mathrm{ppm}$ oxygen and $26,200 \mathrm{ppm}$ hydrogen is shown in Figure 14. The break-point $\mathrm{T}_{1}$ is rather sharp; it can clearly be determined to within $1^{\circ}$ or $2^{\circ} \mathrm{K}$. The cooling curve for the alloy containing $6300 \mathrm{ppm}$ of hydrogen is not shown, but the temperatures $\mathrm{T}_{1}$ are plotted in Figure 15 on the Arrhenius plot. One sees that both points fit right on the line for the oxygen-free tantalum which was determined in this work. Thus, there seems to be no influence of oxygen on the solvus temperature, although the time required to reach equilibrium is much increased by the presence of oxygen.

\section{Deuterium Solubility in Pure Tantalum}

The temperature of the solvus for two alloys of tantalum containing 1 and 4 at. $\%$ deuterium were measured by the procedure just described. Since the diffusion coefficient of deuterium in tantalum is known to be smaller than that of hydrogen at the same temperature, the cooling procedure was the slow-process just described for the Ta-0-H alloys。 In this instance, the time required to reach apparent equilibrium just below $\mathrm{T}_{1}$ for the alloy containing 1 at.\% was about 2 
hours and for the alloy containing 4 at.\% about 1 hour. Again, the cooling curves showed nice sharp breaks and the temperature $\mathrm{T}_{1}$ could be determined to within a $1^{\circ}$ or $2^{\circ} \mathrm{K}$. The results of these two experiments are plotted on an Arrhenius plot in Figure 16. Data fit nicely on the solvus line obtained for tantalum containing hydrogen of mass 1 . These results are quite different, however, from those reported by Cannelli and.Cantelli。25 Apparently, the effective cooling rate of less than $1^{\circ} \mathrm{K}$ per hour in the present experiment was sufficiently slow to permit equilibrium to be established for this slow diffusing isotope, whereas the cooling rate of $12^{\circ} \mathrm{K}$ per hour used by Cannel1i and Cantelli was not slow enough. There seems no reason to believe that the electrical resistance measurements of the present study and the internal friction measurements of the earlier study should give inherently different results.

\section{Influence of the Cooling Rate}

A complete set of alloys has been examined using heating and cooling rates much faster than those described in the previous measurements, rates of the order of $1^{\circ} \mathrm{K}$ per minute. The value of $\mathrm{T}_{1}$ obtained for alloys of composition $4 \%$ is closely the same as that obtained with the slower cooling rates, but alloys of lower composition gave results departing significantly from the observations quoted above. Not all of 
the observations will be described in detail since the measurements are clearly non-equilibrium, but some of the results will be presented.

A typical result is that shown in Figure 17 for an alloy containing $6000 \mathrm{ppm}$ oxygen and $6300 \mathrm{ppm}$ hydrogen. This heating curve shows a hysteresis similar to that described in Figure 9 , except that the temperature $T_{2}$ (the first break-point upon heating) is higher than that of $T_{1}$ 。 on the second heating and cooling, the temperatures $T_{1}$ and $T_{2}$ are the same; but both are higher than either $\mathrm{T}_{1}$ and $\mathrm{T}_{2}$ on the first cycle. These results are strikingly similax to the hysteresis loops observed by Holmquist as drawn in Figure 6.18

other liloys studied under these conditions of cooling were Ta containing 6000 ppm oxygen and 26,200 ppm hydrogen and $\mathrm{Ta}$ containing deuterium or hydrogen of compositions 1 at.\% or higher. The detailed hysteresis loops are not shown for these alloys but they are similar to those of Figure 17 . The values of $\mathrm{T}_{1}$ for the several experiments carried out are plotted in Figure 18 and are compared with the results obtained for $\mathrm{Ta}-\mathrm{D}$ alloys by Cannelli and Cantelli。 25 For compositions below 2 at.\% the present measurements agree well with their line for deuterium. For compositions of $3 \%$ and $4 \%$ hydrogen the results fall between the two curves; this indicates that precipitation is easy enough in the $\mathrm{Ta}-\mathrm{H}$ system that even this faster cooling rate is nearly slow enough to permit equilibrium 
to be achieved at the solvis temperature.

This set of observations shows again that deuterium

and hydrogen have the same apparent solvus line at this faster

cooling rate but that the rate is too rapid for equilibrium

to be achieved for both systems. 


\section{DISCUSSION}

This set of observations is concerned with four principal features of the phase diagram:

1. The solvus line for hydrogen in tantalum.

2. The solvus line for deuterium in tantalum.

3. The effect of oxygen on the kinetics of precipitation and the equilibrium solvus line.

4. The hysteresis in the precipitation and dissolution of the hydride.

The solvus line for the phase diagram of hydrogen dissolved in pure metals usually obeys a simple exponential law

$$
C=C_{0} e^{-\Delta H_{S} / R T}
$$

The heat of solution $\Delta \mathrm{H}_{S}$ for the hydride is about 2150 calories per gram atom of hydrogen in tantalum. This value is lower than that for hydrogen in either niobium or in vanadium. The solubility lines for all three of these metals are drawn in Figure 19. Vanadium has the least solubility at these low temperatures and the highest heat of solution, about 3900 calories per gram atom. 11 Niobium is intermediate; it has a heat of solution of about 2750 calories per gramatom.16 If these lines are extrapolated to $1 / T=0$, the values of $C_{0}$ thus obtained are about the same for tantalum and niobium; vanadium has a value more than twice that size. Values of $C_{0}$ $\Delta \mathrm{H}_{s}$ for the three are tabulated in Table II. Differences in 
Table II. Solubility Constants for Hydrogen $\mathrm{Dissolved}$ in $\mathrm{V}, \mathrm{Nb}$ and $\mathrm{Ta}$

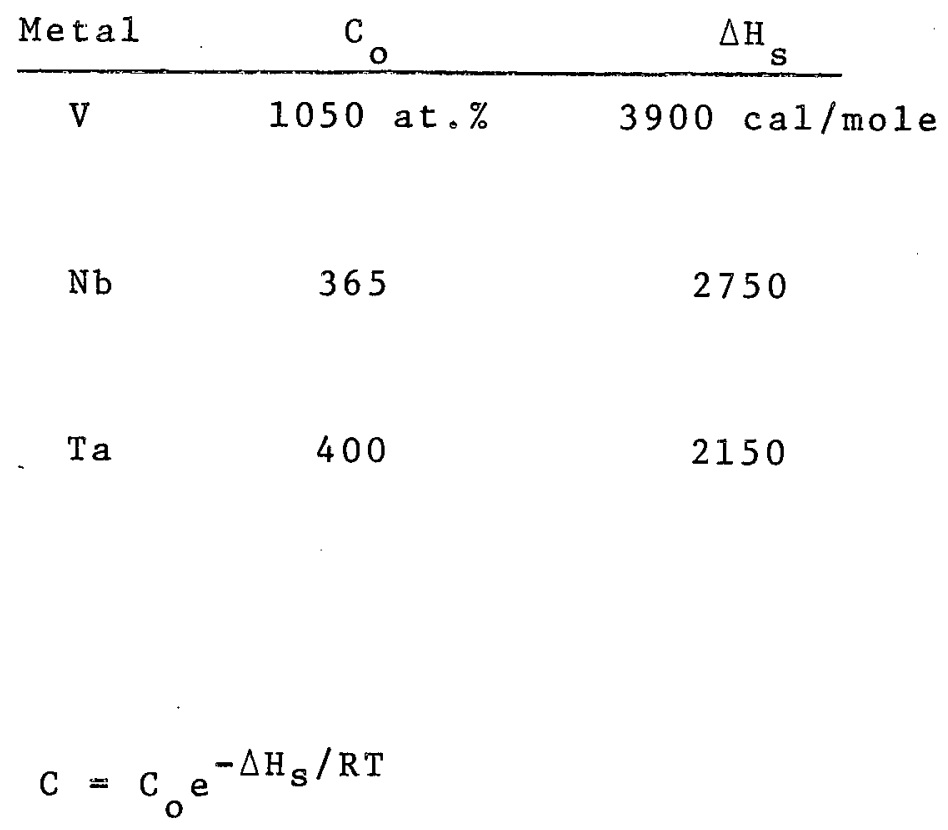


in $C_{0}$ may be caused by possible differences in the $\alpha$ phase itself by differences in the $\beta$ phases.

Examination of the solubility line in Figure 13 and consideration of the overall solvus line in Figure 1 does not permit any conclusions to be drawn about the influence of ordering reactions in the $\beta$ phase observed near room temperature by Saba and co-workers. 26 some slight changes in the solvus line ought to be observed but the compilations of measurements one can make for the tantalum-hydrogen system is not accurate enough to show any possible deviations from a simple Arrhenius behavior.

The present observations on the solubility of deuterium in tantalum were made for only 2 specimens. However the data points obtained in these measurements fitted so well on the solvus line for hydrogen that no point seemed served by continuing measurements to alloys of other compositions. The alloys of tantalum and deuterium thus behaved the same way as do alloys out of niobium with hydrogen and deuterium; the solvus line is the same for both isotopes. It does differ from the effect for vanadium where the solubility of deuterium is considerably higher than the solubility of hydrogen at the same temperature.

Striking effects on the kinetics of precipitation may be observed by altering the rate of cooling through the solvus temperature. For alloys in the composition range of $2 \%$ or lower, 
cooling rates of $1^{\circ}$ or $2^{\circ} \mathrm{K}$ per hour seem sufficient to permit equilibrium to be achieved at all temperatures near the solvus temperature. However, when the cooling rate is increased to values in the vicinity. of $1^{\circ} \mathrm{K}$ per minute, considerable undercooling is observed for these dilute alloys. This is apparent from comparisons of the data plotted in Figure 13 and in Figure 18. At higher compositions, above 4 at.\%, the supercooling even at the faster cooling rate is insignificant. The present measurements cannot decide whether this is an effect of higher diffusion rates at higher temperatures or of differences in scale of the precipitate size。

For tantalum containing deuterium the kinetics are a little different. Deuterium diffuses more slowly in tantalum than does hydrogen. over the temperature range of the present measurement the difference is about 3 to 5 times slower; see the lower two curves of Figure $20.27,28$ Thus rates of cooling necessary to avold supercooling are even slower for the deuterium alloys than for the hydrogen alloys. Unfortunately for the interpretation of the observations made by Cannelli and Cantelii, their cooling rates for the hydrogen and deuterium alloys span this crucial gap and they are misled into believing that the solvus line for deuterium in tantalum is different from that for hydrogen in tantalum; see Figure 10 of their paper. 25 Further credence for this interpretation of their data may be seen by considering the alloy of highest composition in their 
measurements; this alloy contained about $8 \%$ deuterium. (See their highest point in Figure 10 of their papero) It departs from linearity of their six alloys of lower composition and tends toward their line for hydrogen in tantalum. Thus it shows the same behavior as is seen in Figure 18 of the present work.

The data for diffusion coefficients of hydrogen and deuterium in vanadium and niobium in Figure 20 give a hint of one reason that supercooling may be less important in vanadium than it is in niobium and tantalum.29 Diffusion coefficient at a given temperature, say $200^{\circ} \mathrm{K}$ for vanadium is nearly four orders of magnitude higher in vanadium than in tantalum. Thus equilibrium should be much easier to achieve in that system. Niobium presumably should be intermediate between the two, but Westlake and ockers have shown the same difficulty of preventing supercooling in those alloys that are found in the present study for tantalum.17 Consequently nucleation of the $\beta$ phase and the fineness of dispersion of the resultant hydride may also play a significant role in supercooling.

Aditions of oxygen in solid solution do not appear to affect the equilibrium solvus line for hydrogen in tantalum, see Figure 15. However, the rate of approach to equilibrium is altered significantly by the presence of oxygen; much slower cooling rates are required to prevent supercooling when oxygen is present. This might be caused by the hardening effect of 
oxygen which could alter the thermodynamics of precipitation of the hydride in the tantalum matrix. More likely, though, it is caused by the trapping effect of oxygen for hydrogen, with a consequent slowing of the diffusion rate. The binding energy of a hydrogen atom to an oxygen atom has not been measured for tantalum, but values of about 2000 cal/mole are reported for both niobium and vanadium.11,15. Assuming that binding energy is about the same in tantalum, a hydrogen atom dissolved in tantalum would spend a considerable fraction of its time bound to an oxygen atom at these low temperatures. Thus long-range diffusion through the crystal could be markediy affected by the presence of oxygen. This could account for the much longer times required for achievement of equilibrium in these oxygen-containing alloys.

The final feature requiring explanation is the presence of hysteresis on cooling and heating. Because of the extra difficulty of explanation involved for non-equilibrium cooling; i.e., fast cooling and heating rates, consideration will be given only to curves obtained on slow cooling and heating. The comments to be made are similar to those made by Westlake 16 but the ideas have been developed further after conversations with Westlake. An examination of typical curve such as that in Figure 9 shows the following features. Upon the first cooling, the resistance decreases lineariy until the solvus line is reached; this Is presumed to be $T_{1}(1)$. At this point hydride 
is presumed to form as the hydrogen leaves the solid solution. Since the precipitate is much less dense than the matrix, the volume difference must be accommodated by elastic and plastic strains。 Elastic strains cannot accommodate the total volume difference, so dislocations must be punched out during the growth of the hydride precipitate. The hydride precipitates continuously as the temperature is further lowered. On heating from the lower temperature, small changes in particle size will reverse the sign of the elastic stress; this can be accomplished by very small changes in the hydrogen concentration in the solid solution. This behavior explains why the curved in Figure. 9 tends to be roughly parallel to curve a. Above $\mathrm{T}_{2}(1)$, dissolution of the hydride is only possible by the collapse of dislocation loops and ultimately by generation of dislocation loops of opposite sign. This would explain why curve dends to be parallel to curve b. Complete dissolution of the hydride occurs at $\mathrm{T}_{3}$ 。

Precipitation occurs on a second cooling at a temperature $\mathrm{T}_{\mathrm{I}^{\prime}}$ (2) higher than $\mathrm{T}_{1}(1)$. This can be explained by the fact that some dislocations left after the first cycle would act as nucleation sites for the hydride on the second cooling. Thus on the second cycle less supercooling is needed. Below $\mathrm{T}_{\mathrm{I}}$ (2) the same mechanism as discussed above is applicable. If the hydrides axe roughly in the same geometrical configuration on successive coolings, the heating curve for all cycles 
should be approximately the same. The absence of effect of 0 on the solubility limit under equilibrium conditions supports the theory formulated by Holmquist. 18 His results showed that solution strengthening by an interstitial had no effect on hydride formation. Thus the increase in macroscopic flow stress does not affect the plastic work during hydride nu= cleation and growth. This is consistent with the fact that dislocation loops must be punched in an essentially perfect crystal during the first cooling。 


\section{CONCLUSIONS}

The resistometric method used is an appropriate technique by which hydride precipitation and dissolution can be detected. Nearly equilibrium conditions are essential for an accurate determination of the solubility limit of hydrogen in tantalum. Several interesting features emerge in the determination of the solvus line.

1. The heat of solution $\Delta_{\mathrm{H}}$ f for the hydride is 2150 calories per gram atom in a composition range of 0.5 to 10 at.\%. It is lower than in the $\mathrm{Nb}-\mathrm{H}$ and V-H systems where the heat of solution is respectively 2750 and 3900 calories per gram atom.

2. There is no isotope effect on the solvus line.

3. Oxygen impurities in solid solution up to $6000 \mathrm{ppm}$ do not affect the solubility limit of hydrogen in tantalum。

4. Considerable undercooling is observed by changing the cooling rates. Under equilibrium conditions long-range diffusion appears to be the governing factor on precipitation and growth.

5. The rate of approach to equilibrium is slower for deuterium than for hydrogen. In the temperature range considered the diffusivity of deuterium was 3 to 5 times smaller than that of hydrogen. 
6. Much slower cooling rates are needed to reach equilibrium when oxygen impurities are present. This is probably caused by the trapping of hydrogen by oxygen and a consequent slowing of diffusion rates.

7. There is an hysteresis upon cooling and heating around the solvus temperature even under equilibrium conditions.

8. This hysteresis loop tends to close up upon successive thermal cycles but never disappears completely.

9. Strengthening the matrix with an interstitial impurity such as oxygen does not affect the precipitation temperature. 
Figure 1. The low temperature section of the phase diagram for Ta-H alloys. Some uncertainty exists in the boundary of the $\beta$ phase near room temperature (dotted line)。 


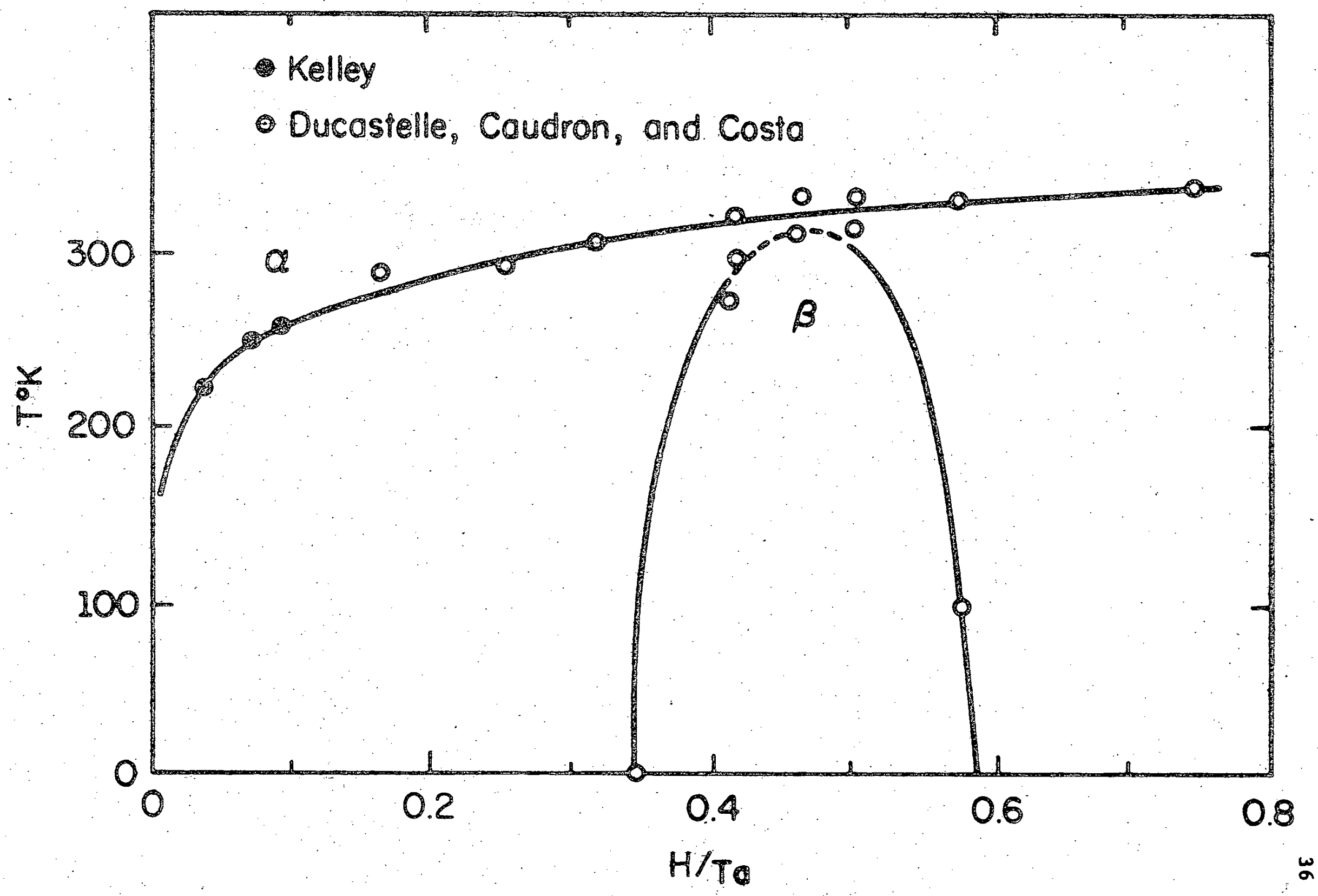


Figure 2. Reported measurements of the solvus line for hydrogen in tantalum and equilibrium with the phase $\mathrm{Ta}{ }_{2} \mathrm{H}$. 


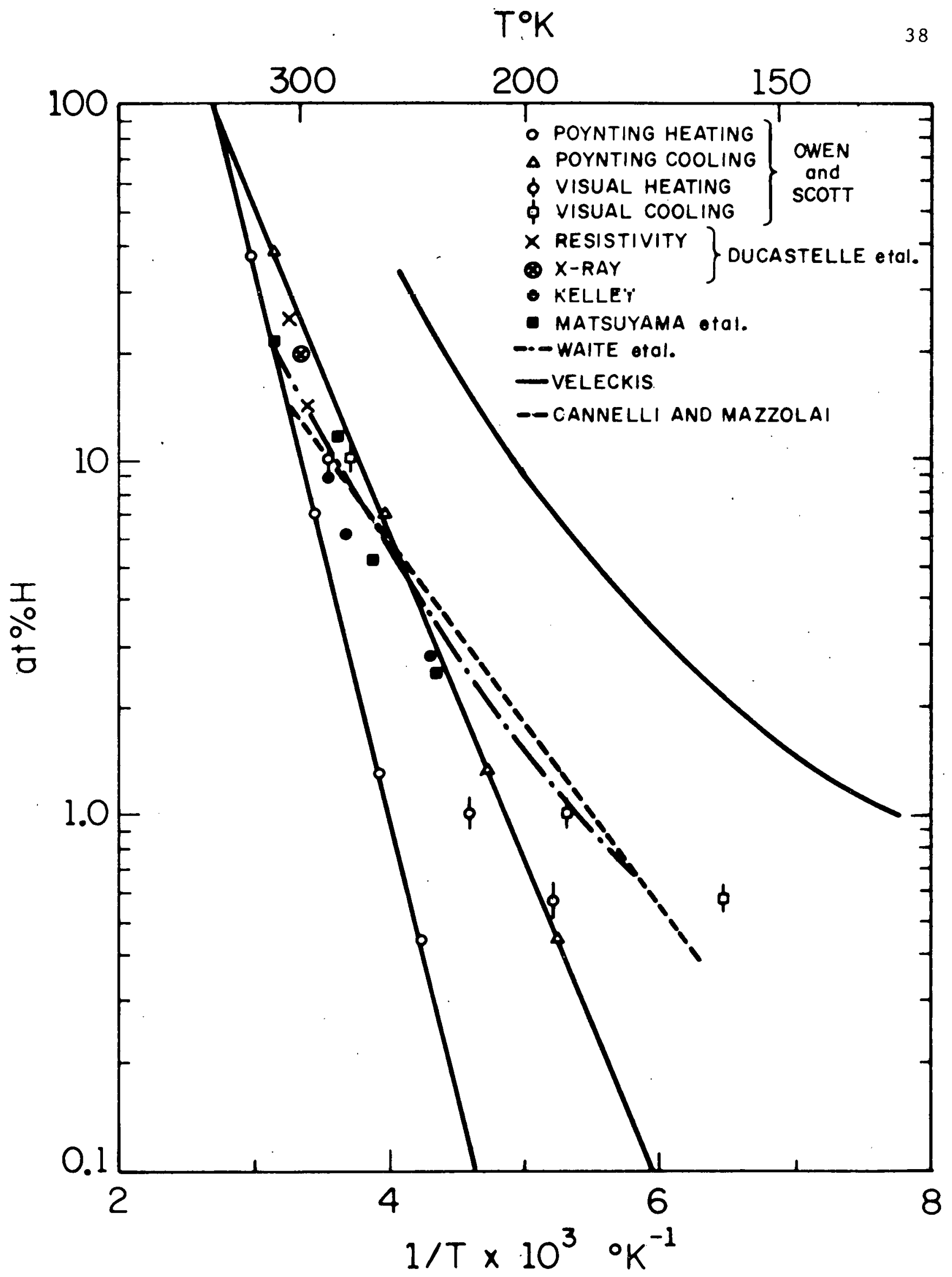


Figure 3. Several of the measurements of solvus line for hydrogen in vanadium. 


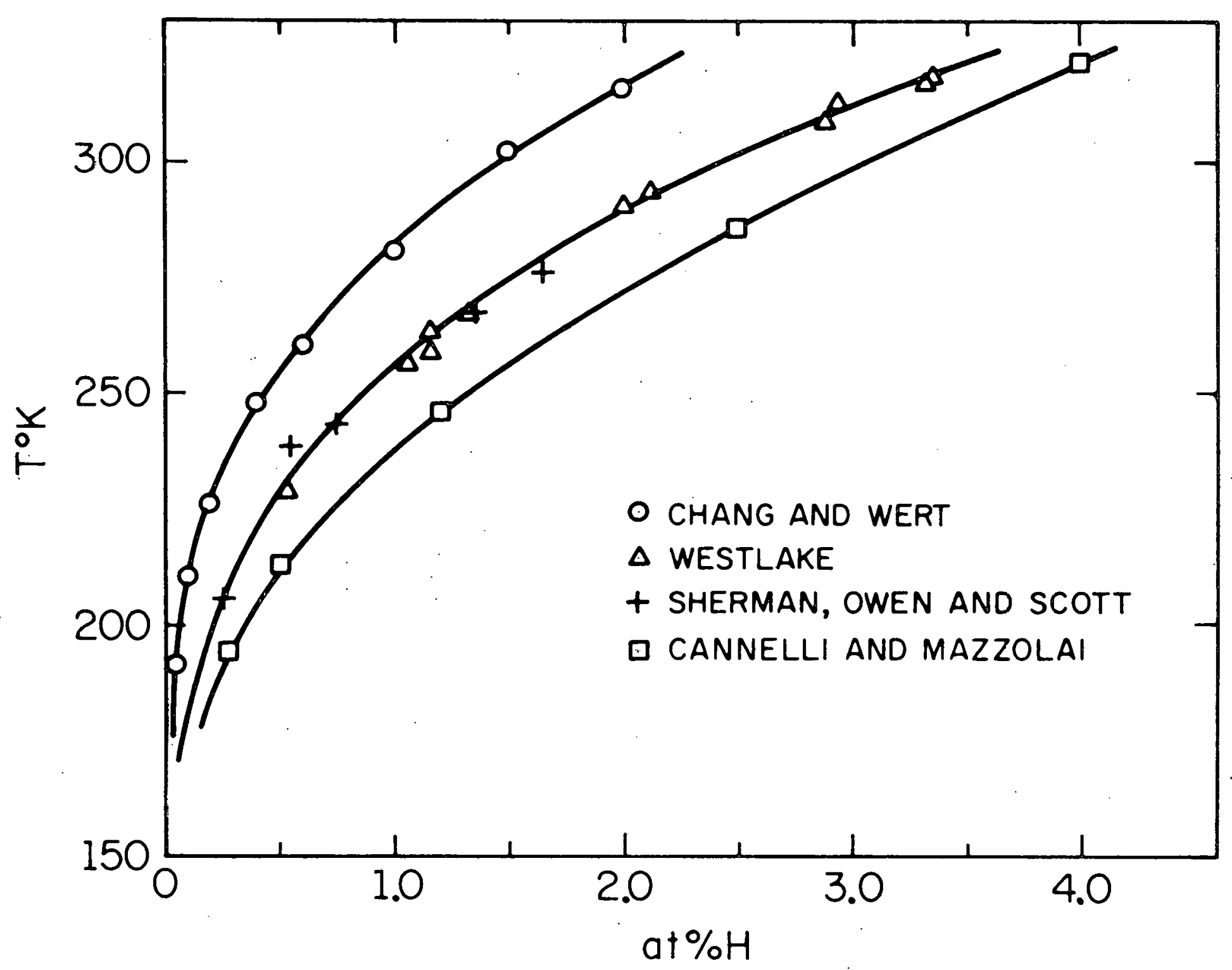




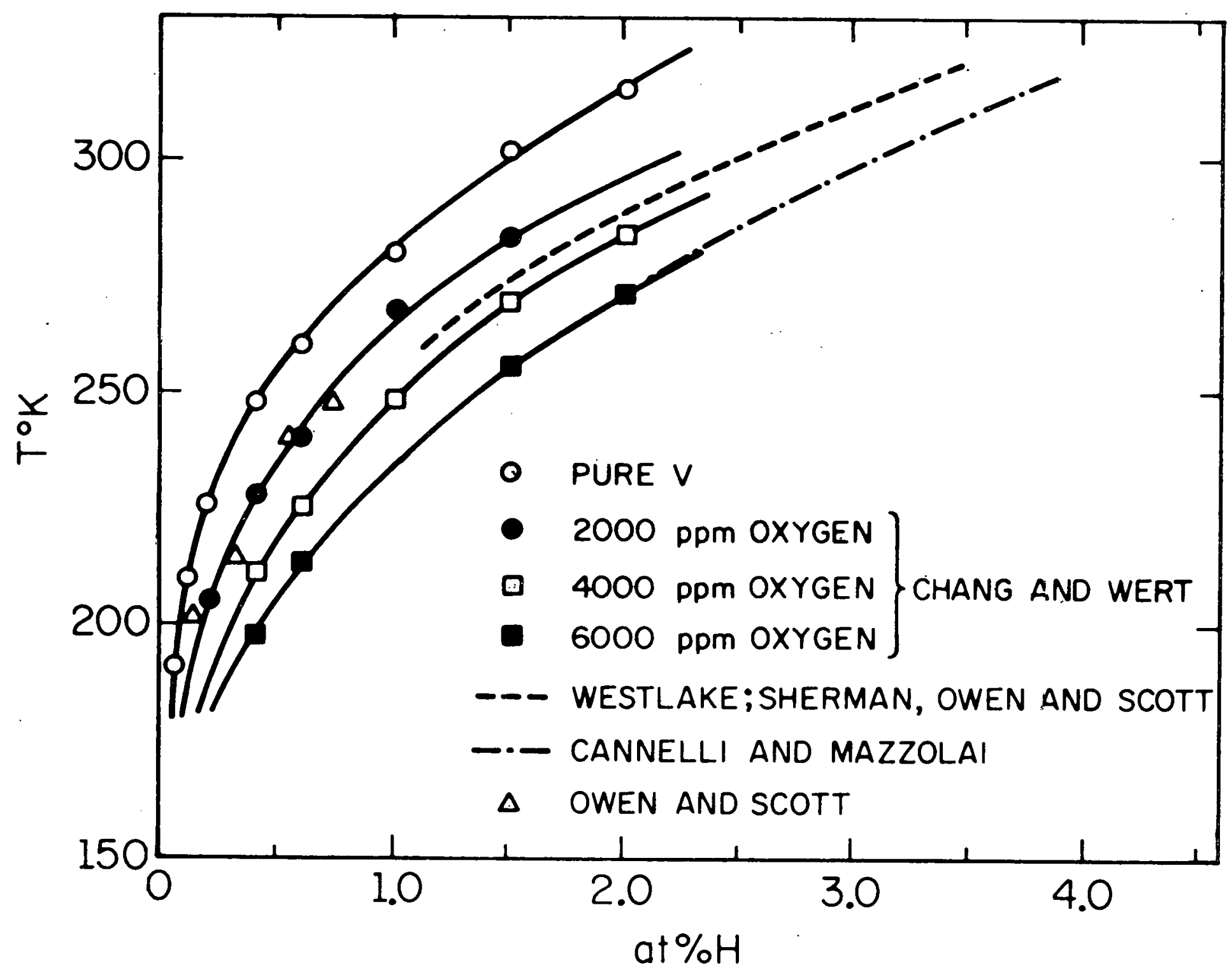


Figure 5. The solubility of hydrogen in niobium and equilibrium with the phase $\mathrm{NbH}$. 


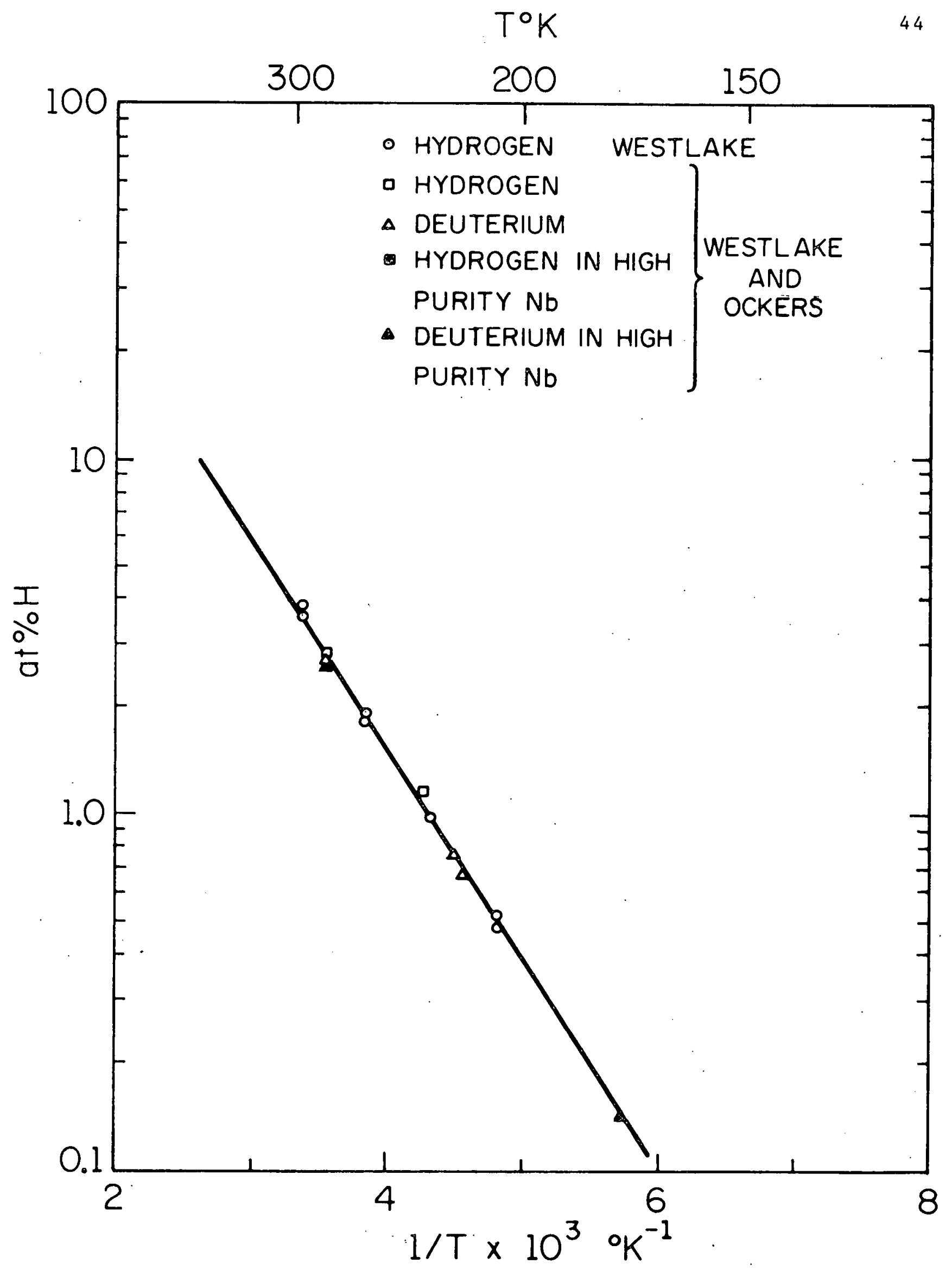


Figure 6. The cooling-heating hysteresis for nlobiumhydrogen alloys. After Holmqu1st. 


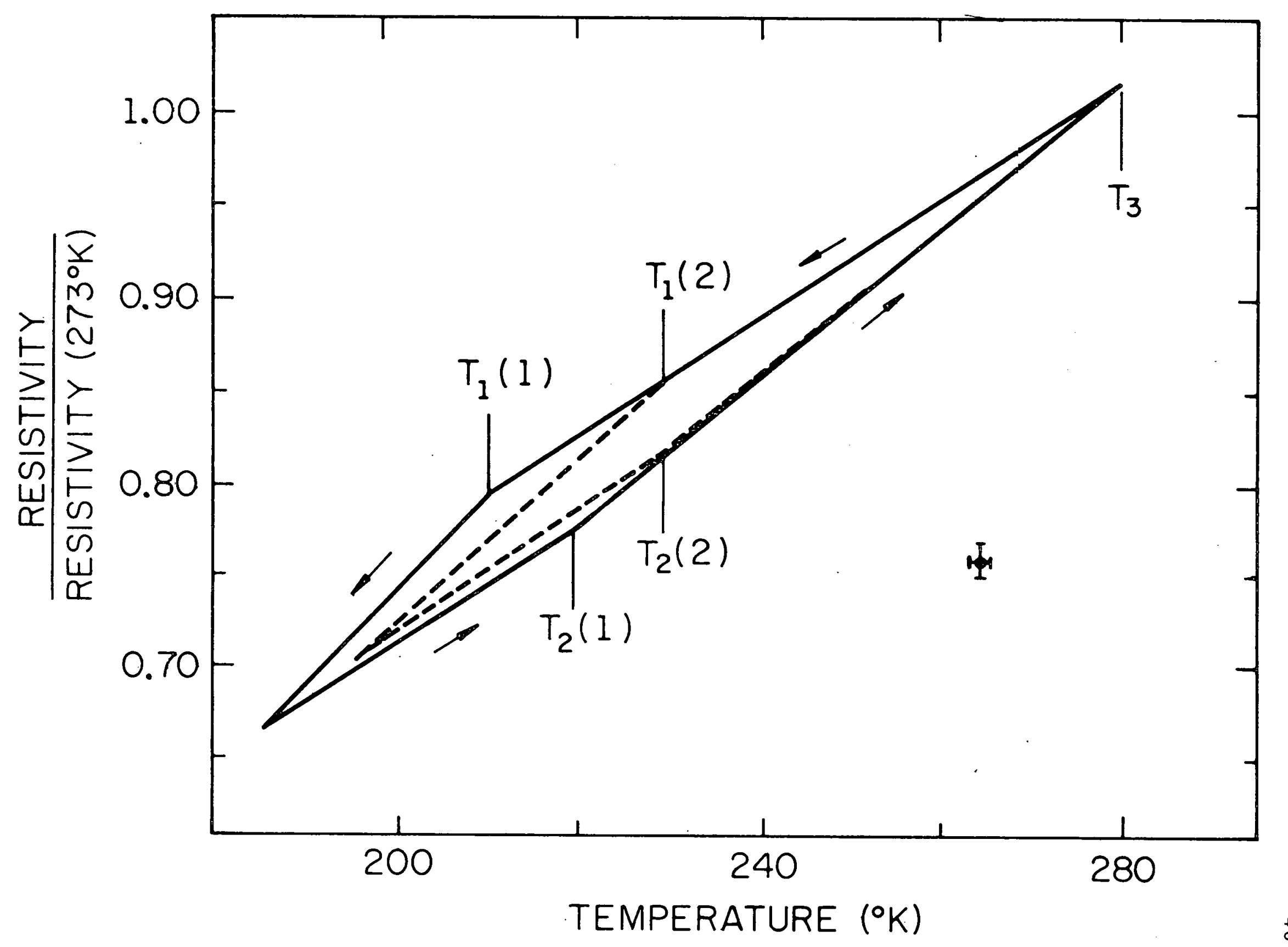


Figure 7. The solvus lines for the Ta-H and Ta-B alloys reported by Canneli and Mazzolai and Cannel1i and Cantelli. 


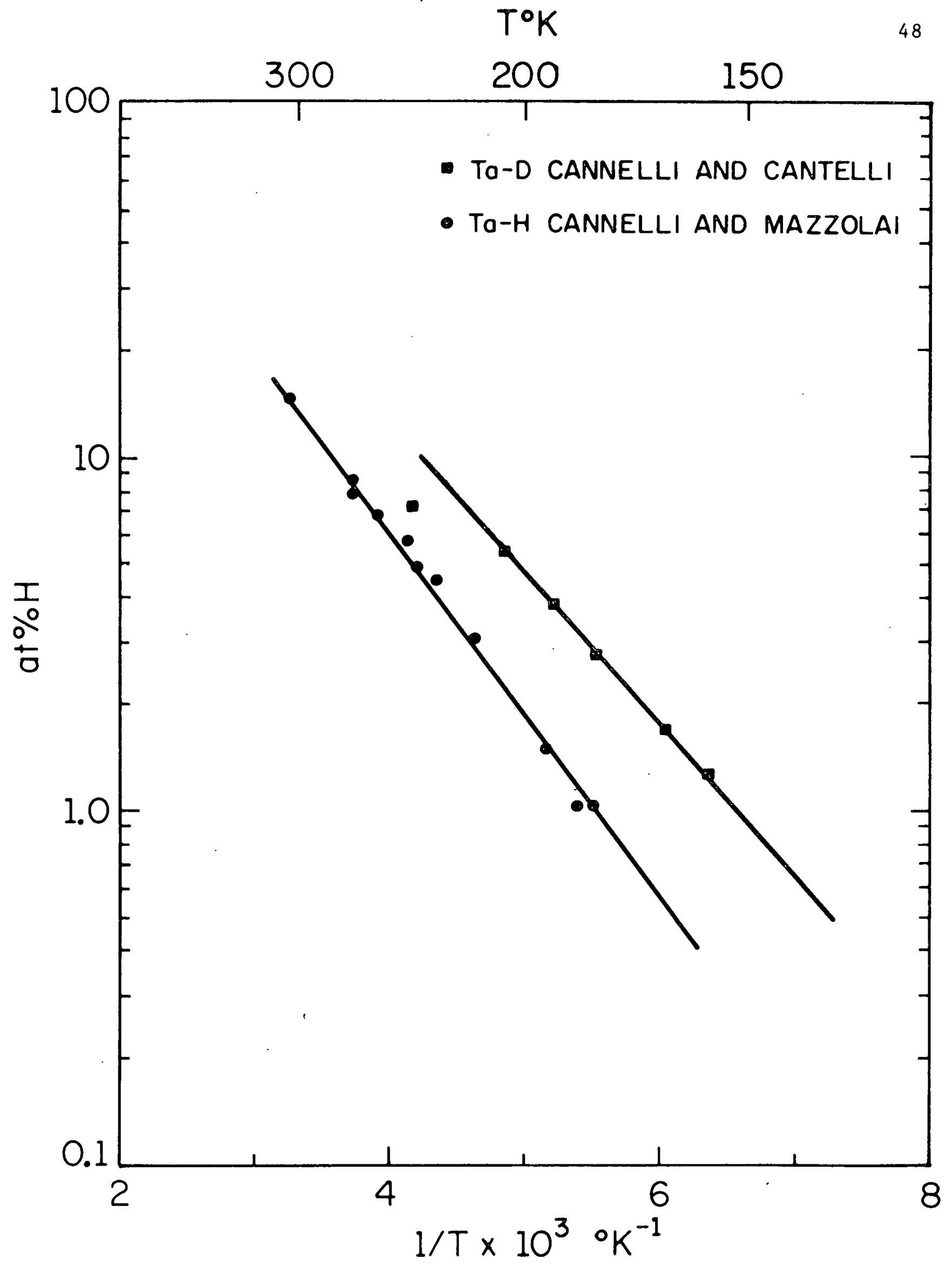


Figure 8. The resistance as a function of temperature for a specimen of tantalum freed of oxygen by a high temperature vacuum treatment. No hysteresis is evident in the cooling-heating cycle. 


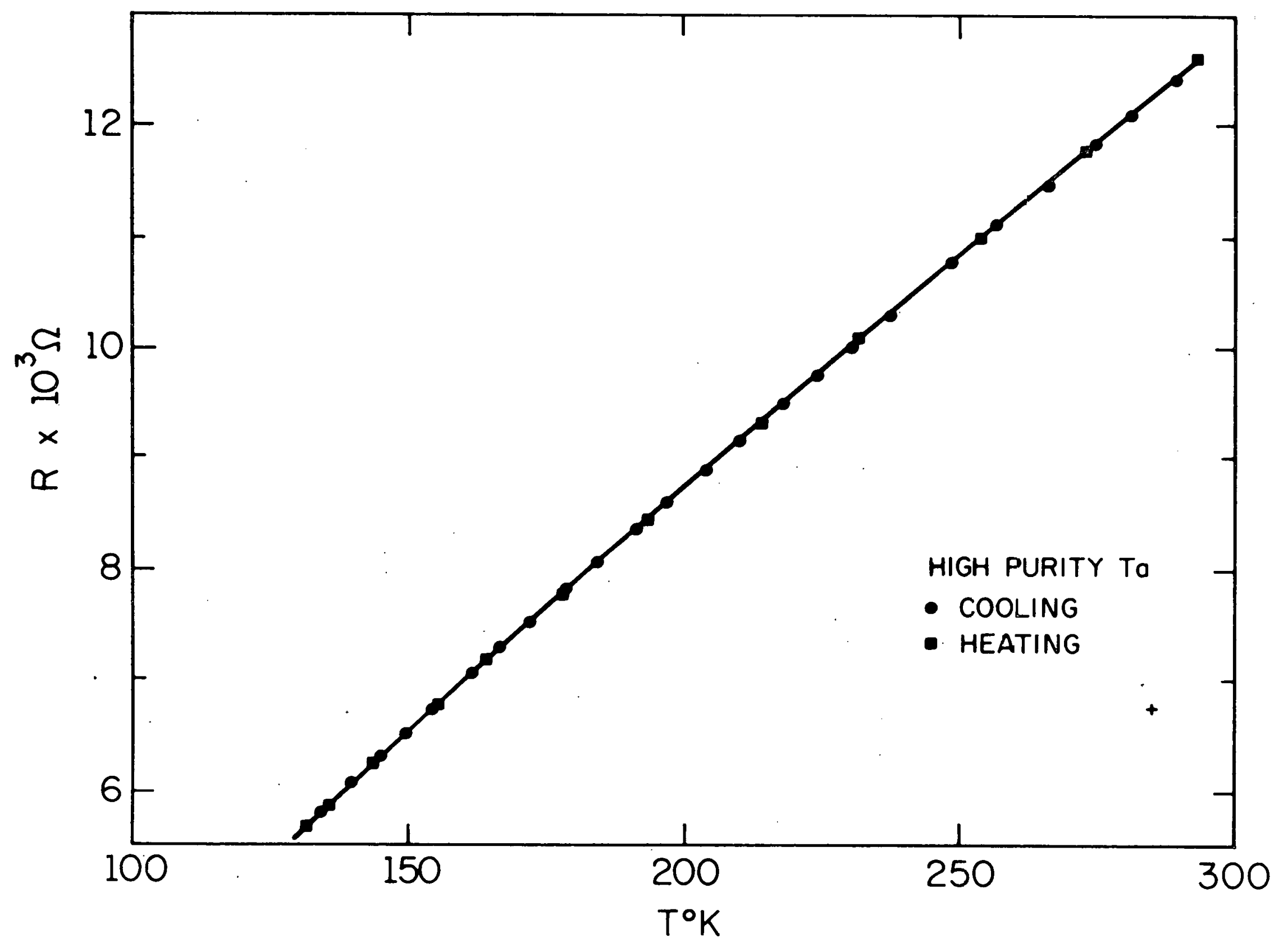


Figure 9. The cooling-heating hysteresis loop for the first and second cooling cycles of a tantalum alloy containing 1.5 at.\% H. The symbols "a" through "e" are referred to later in the discussion. 


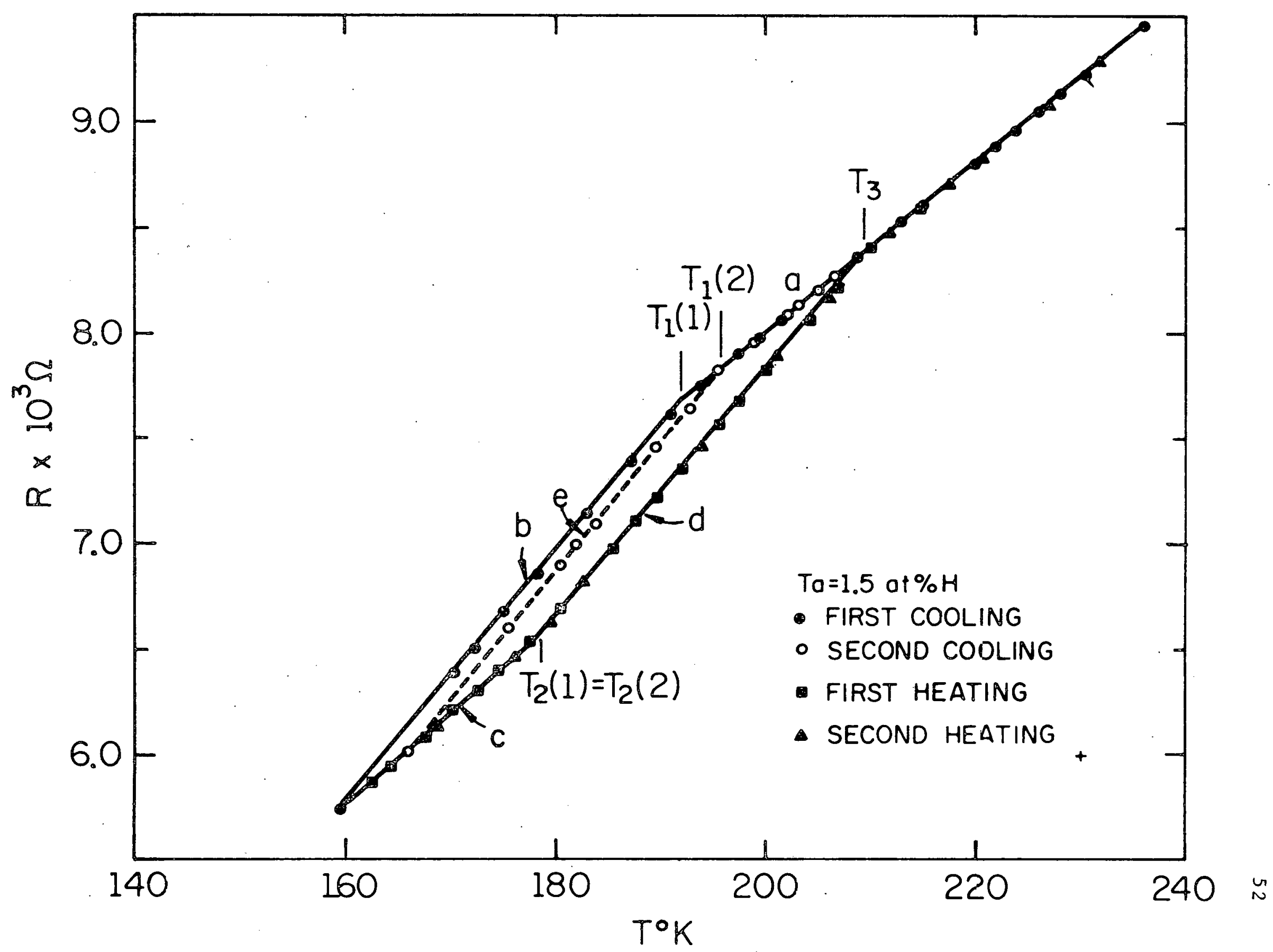


Figure 10. The cooling-heating hysteresis loop for the first and second cooling cycles for a tantalum specimen containing 4 at.\% $\mathrm{H}$. 


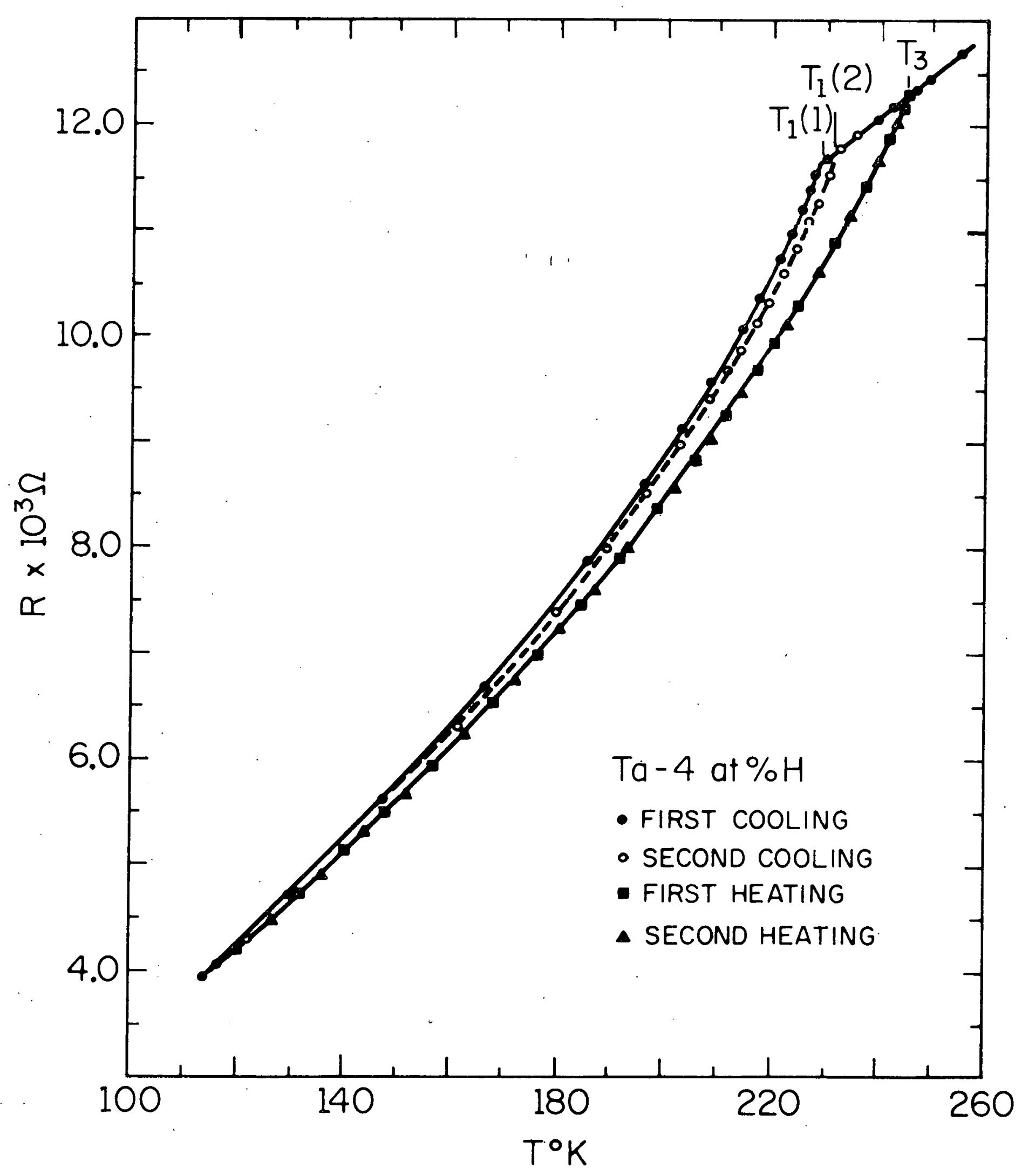


Figure 11. A plot of $\Delta \rho$ as a function of temperature for an alloy containing $0.5 \% \mathrm{H}$. 


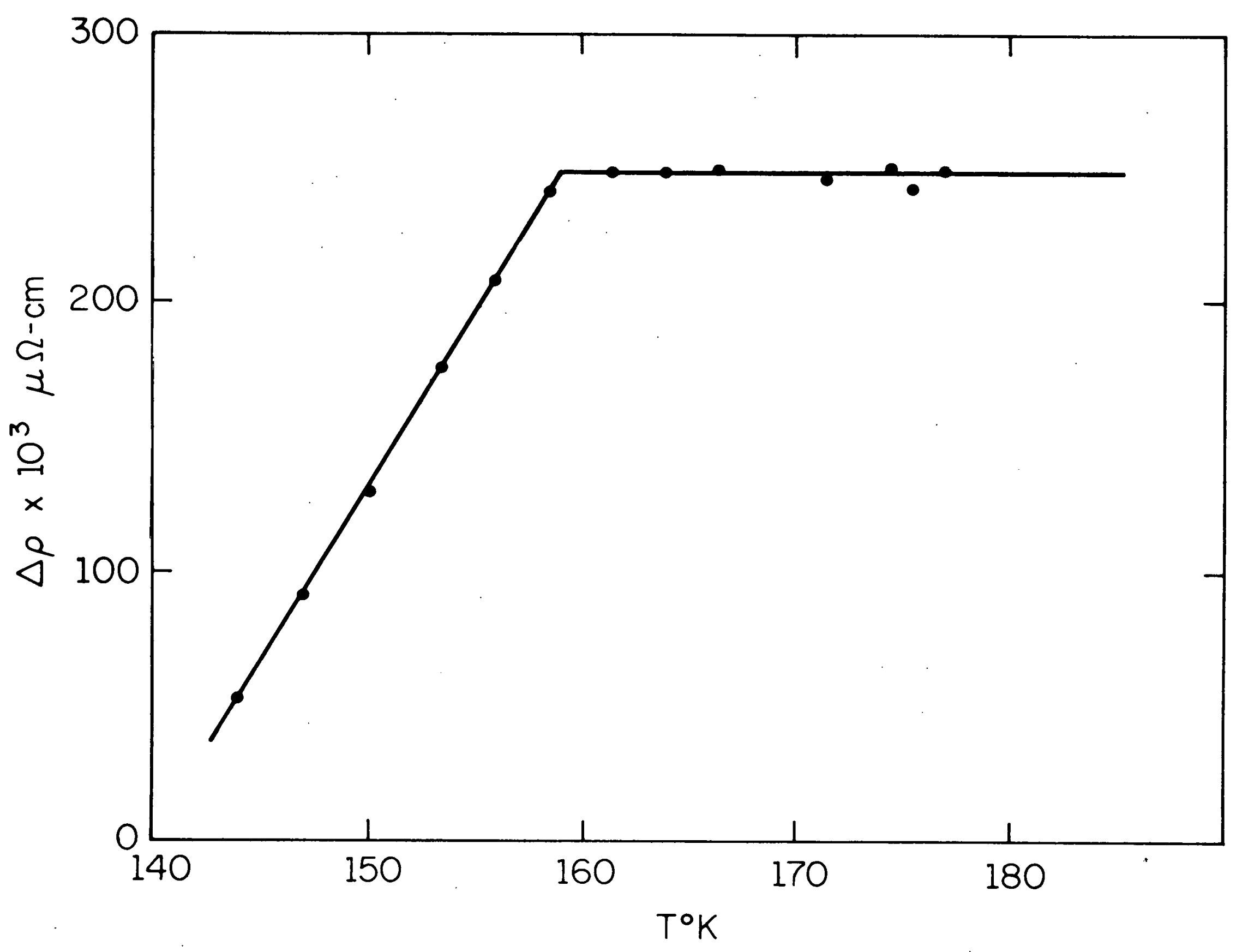


Figure 12. The" measured points on the solvus line for the Ta-H system measured in the present work compared to several previous measurements. 


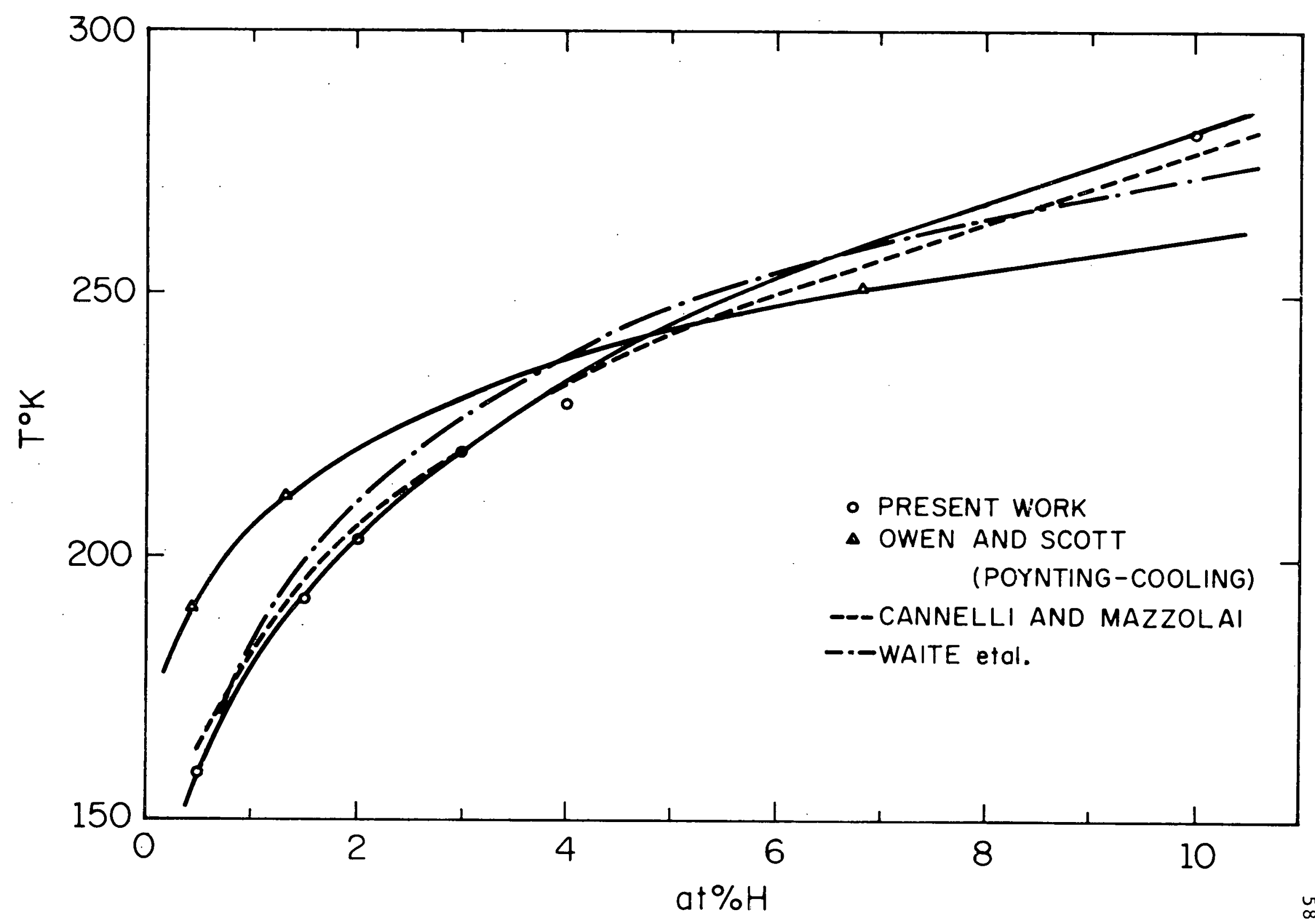


Figure 13. The observations from the present work

compared with those reported earlier for the Ta-H system. 


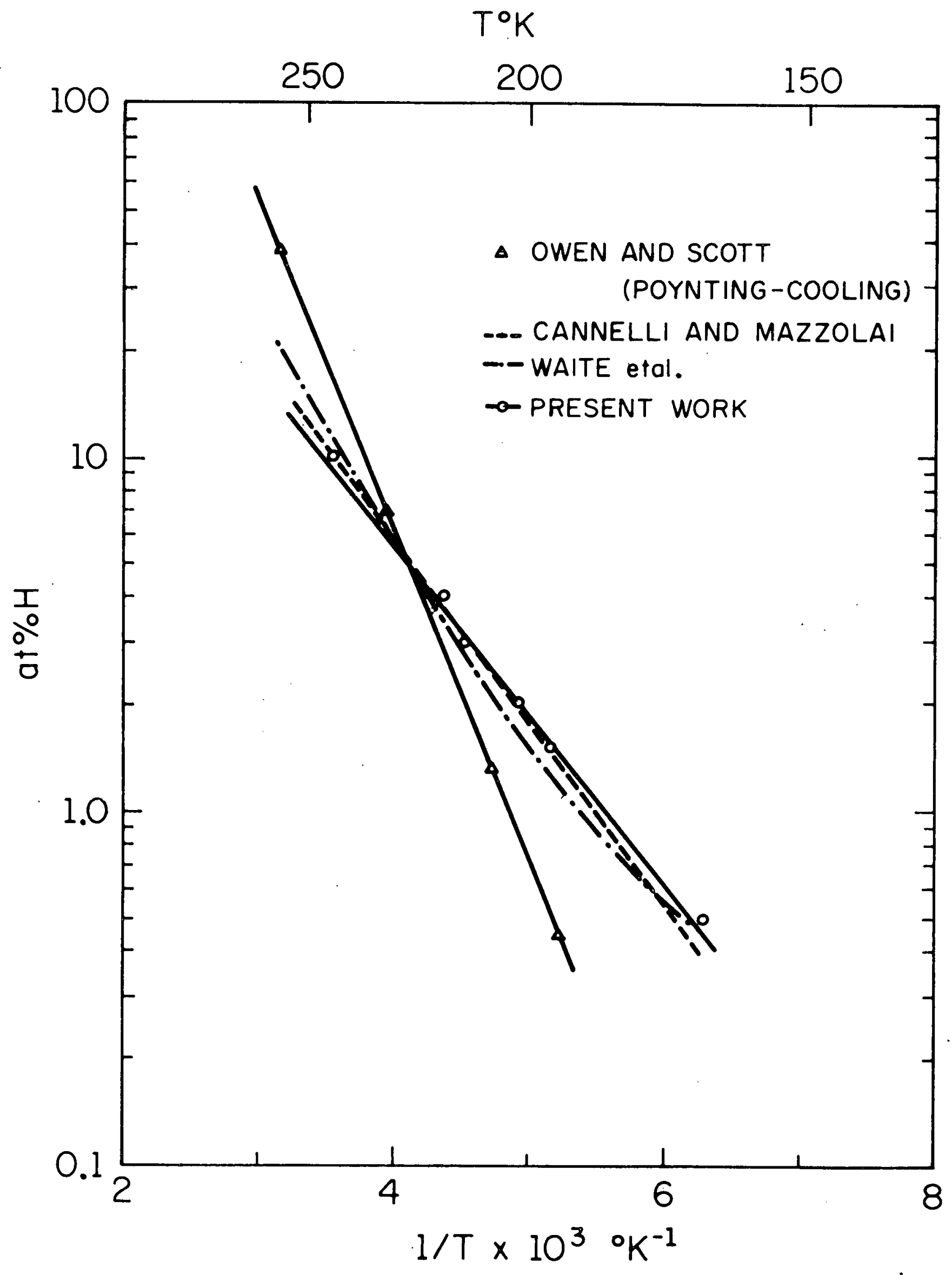


Figure 14. Part of the cooling cycle for a specimen of $\mathrm{Ta}-\mathrm{O}-\mathrm{H}$. 


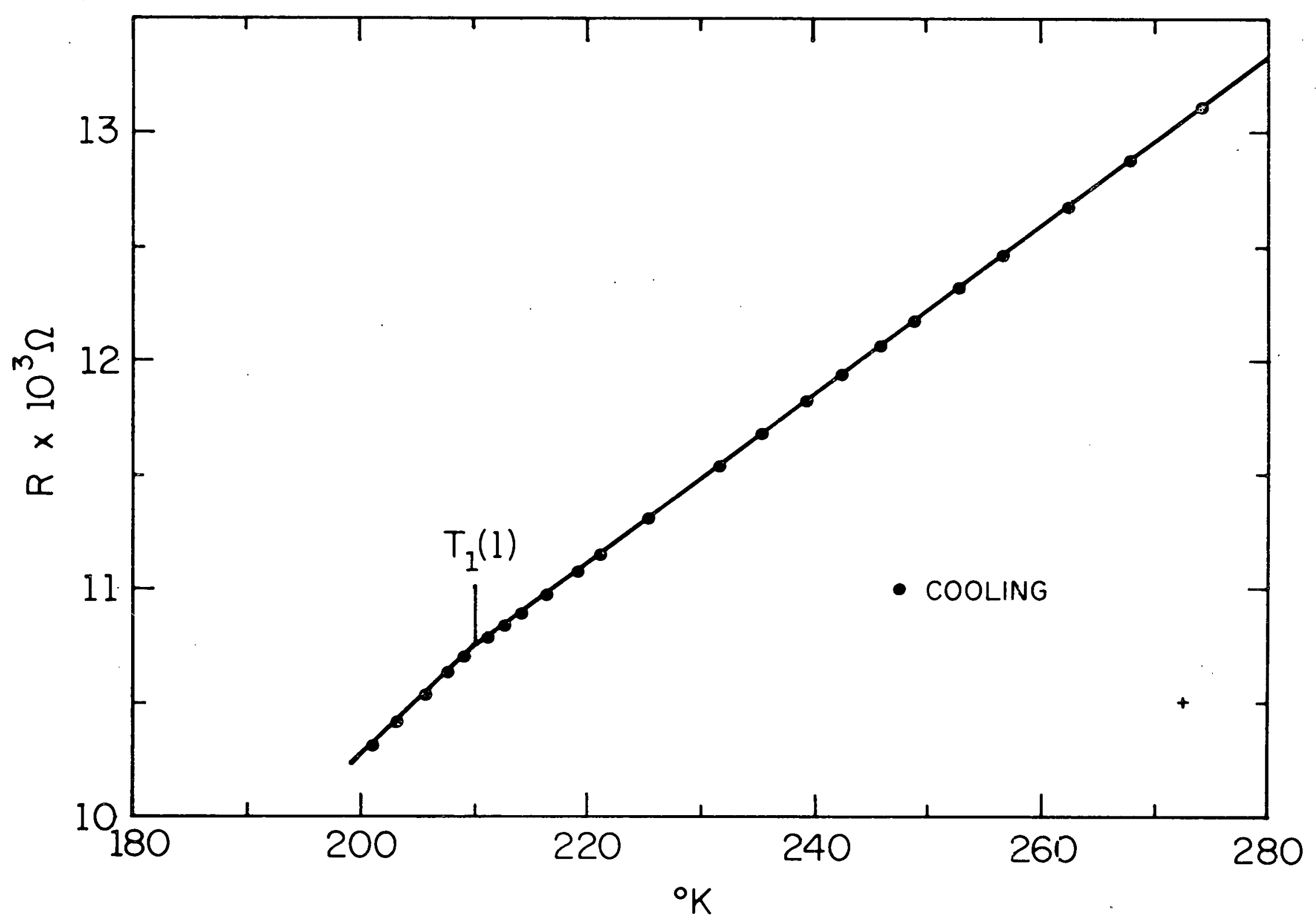


Figure 15. The two measured values of hydrogen solubility in an alloy of $\mathrm{Ta}-\mathrm{O}-\mathrm{H}$ compared to the measured solvus line for hydrogen In tantalum. 


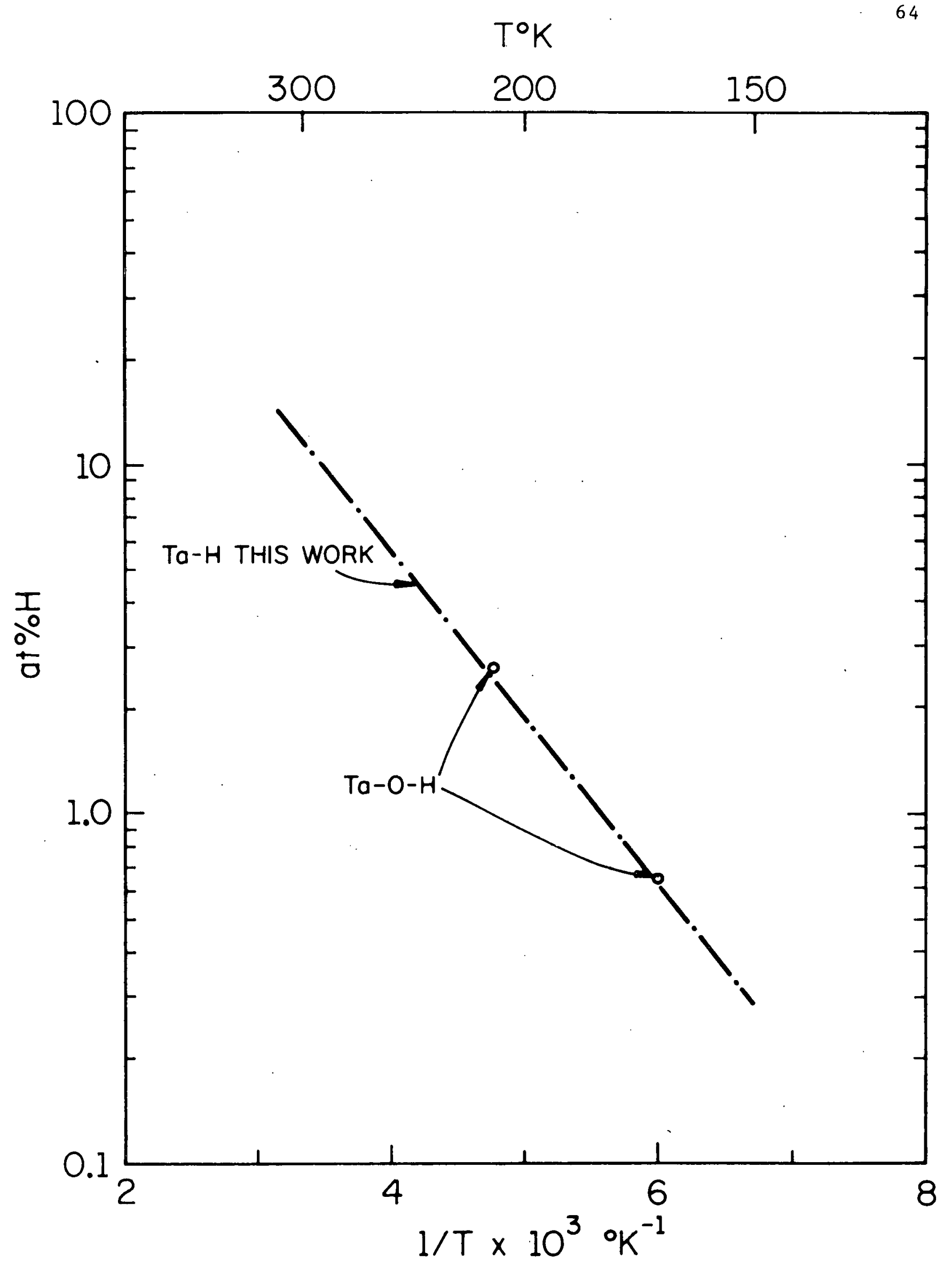


Figure 16. The two measurements of the solubility of Ta-D system compared to the measured solubility of hydrogen in tantalum from this work and to the deuterium in tantalum solvus reported by Cannelli and Cantelli. 


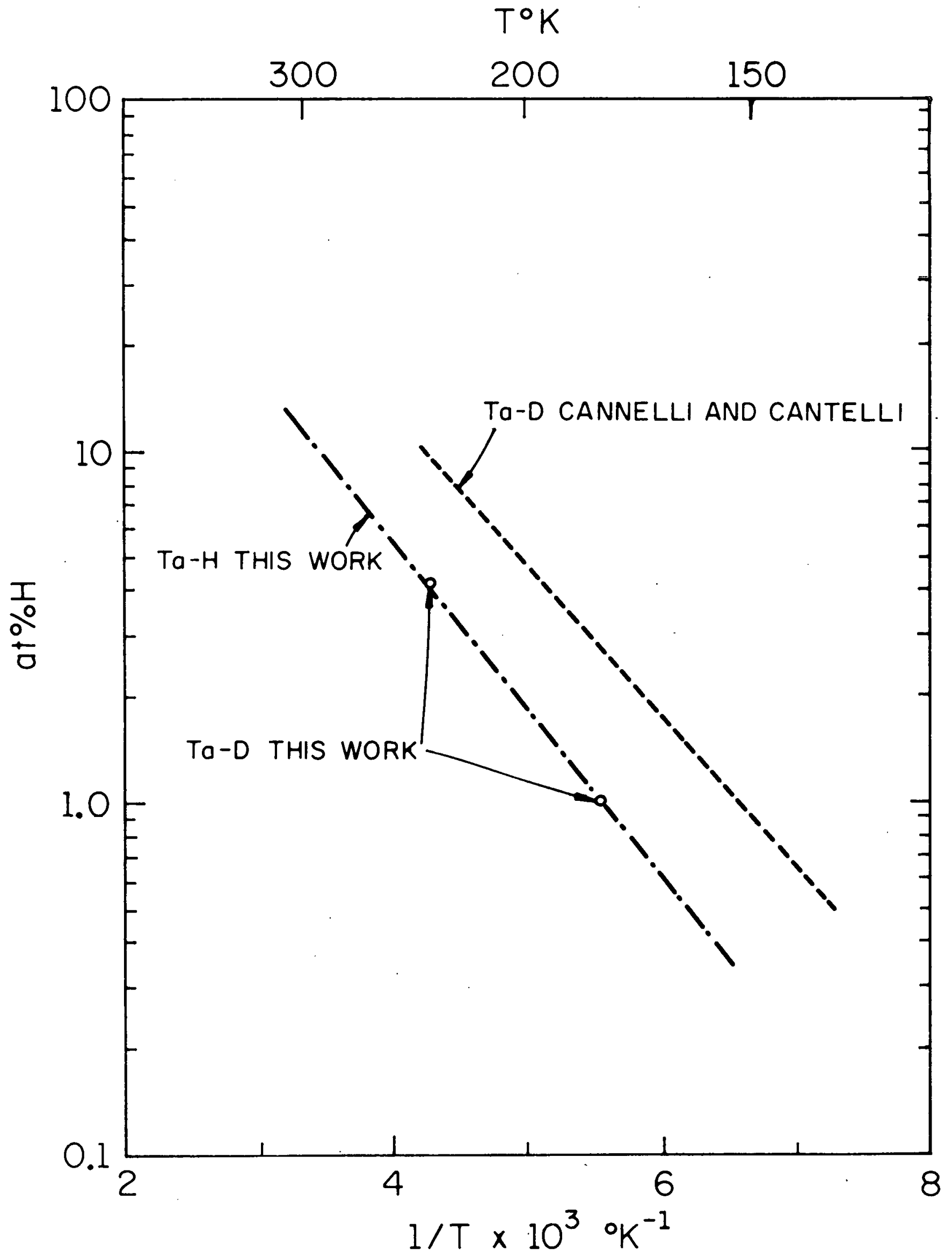


Figure 17. The cooling-heating cycle for a specimen cooled at the rapid rate. 


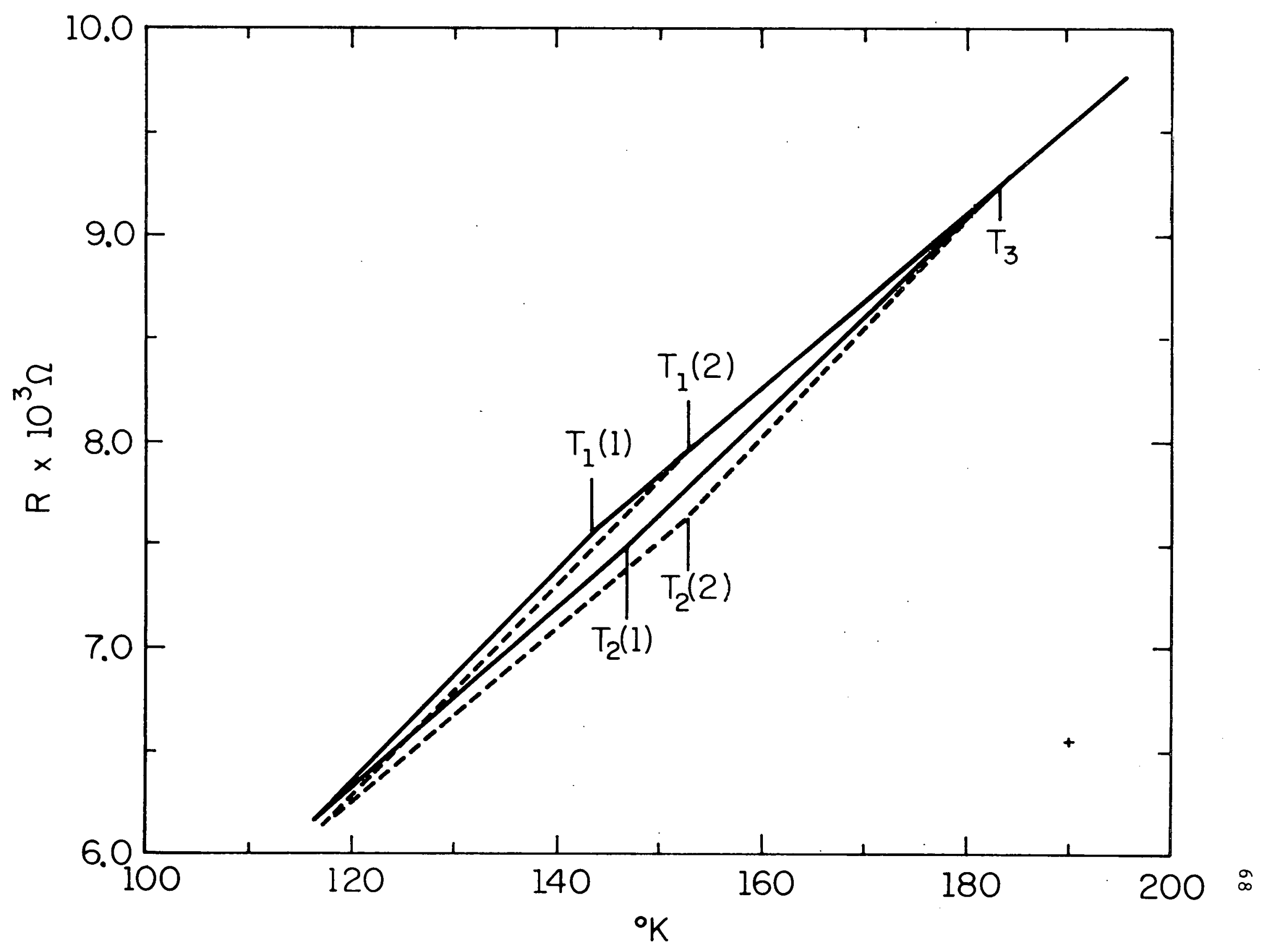




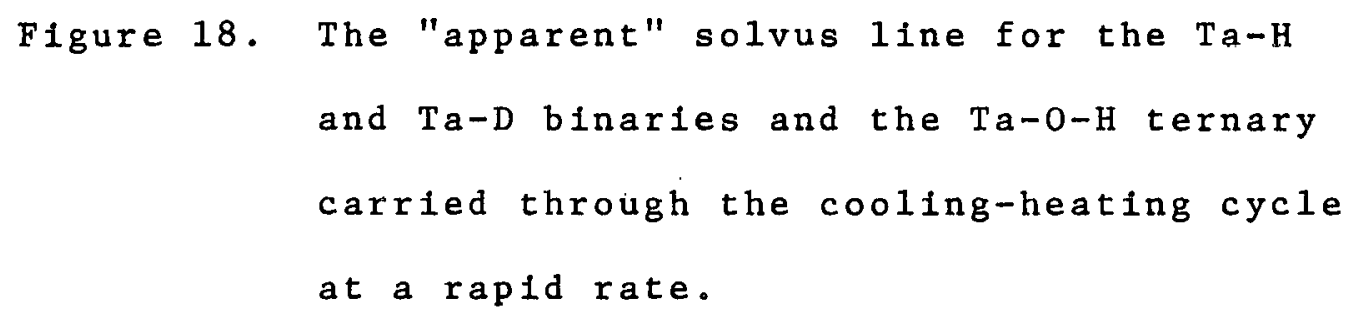




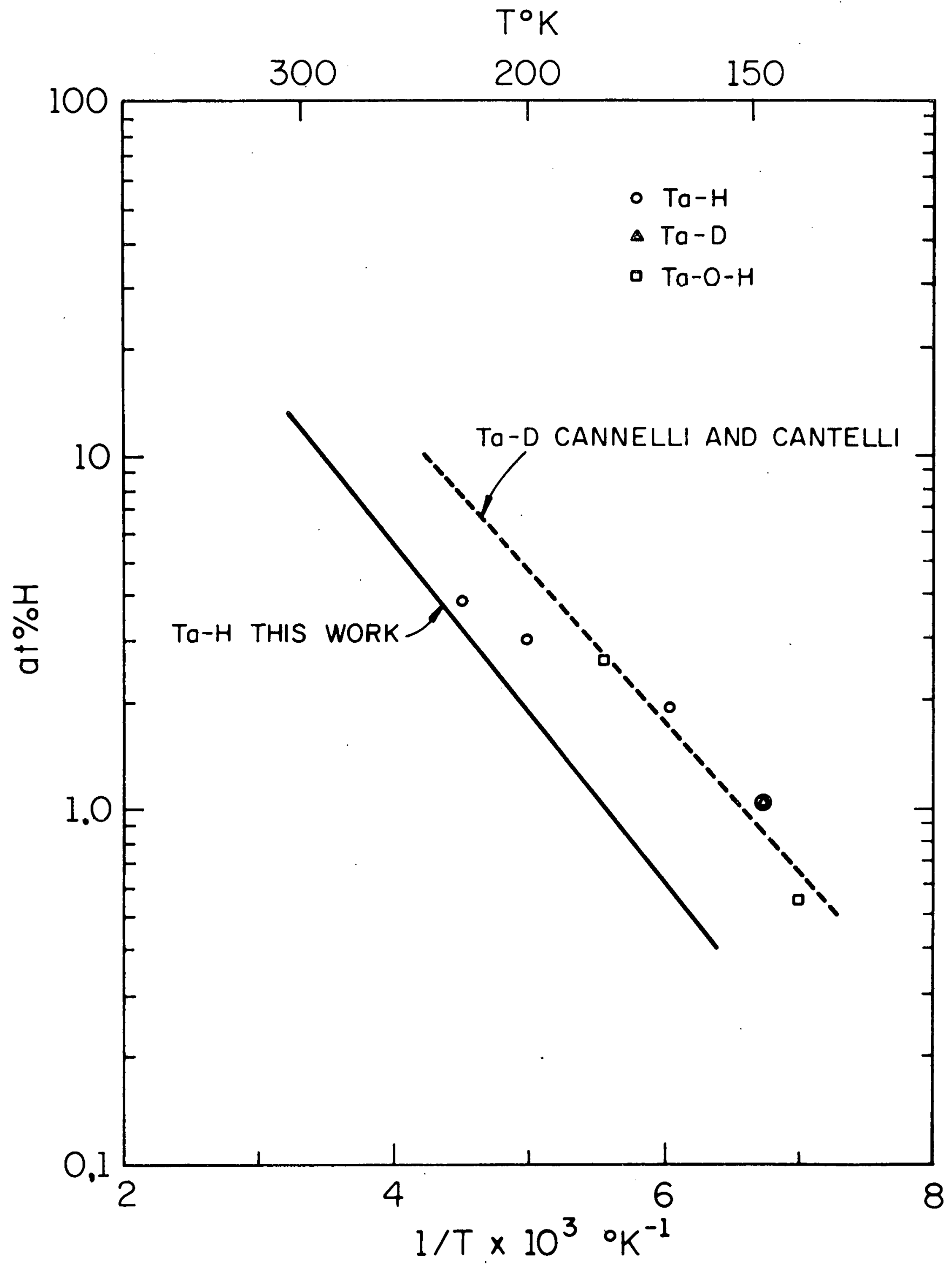


Figure 19. The solvus lines for hydrogen in tantalum, niobium and vanadium. 


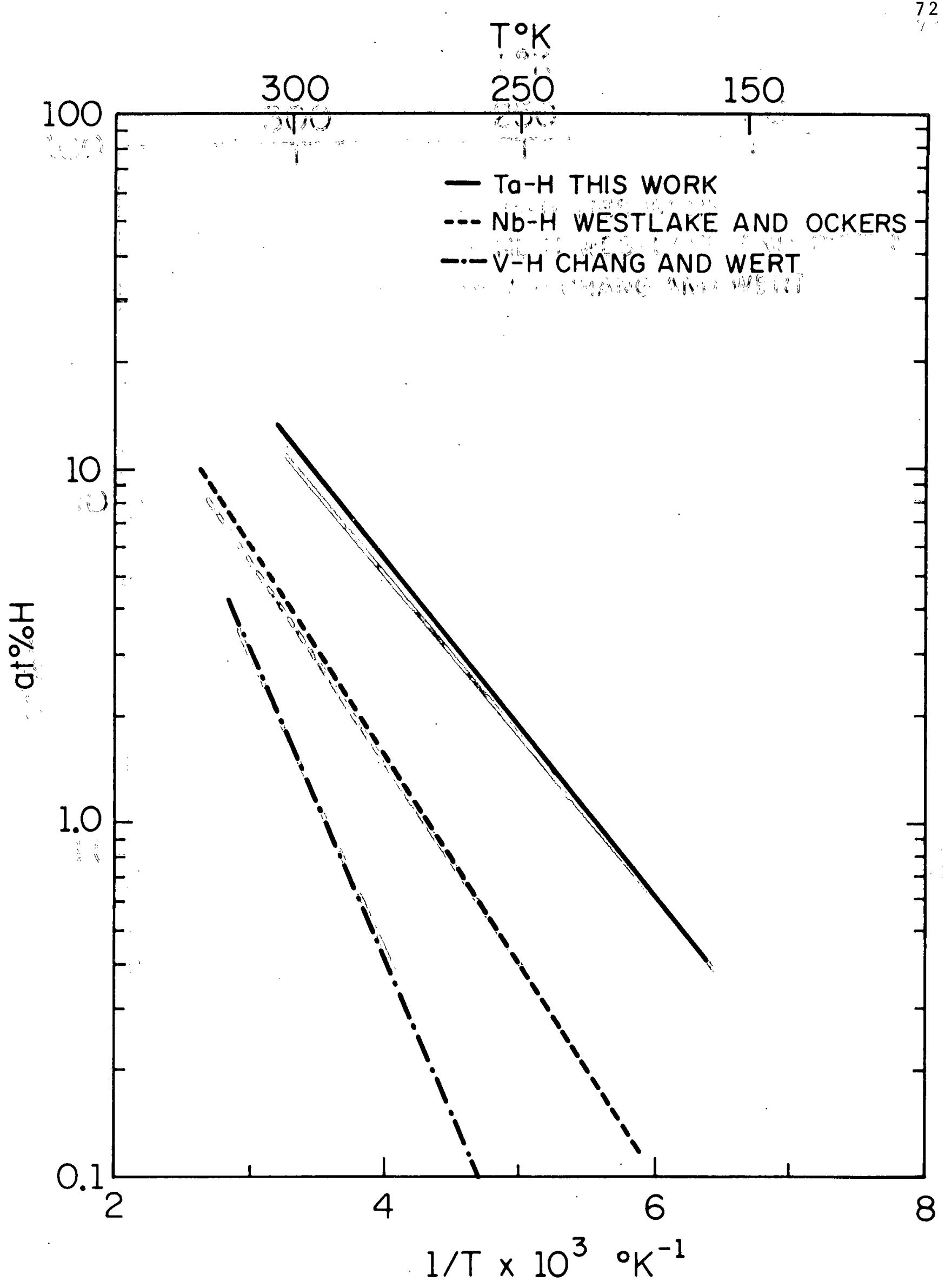


Figure 20. The diffusivities of hydrogen and deuterium In vanadium, niobium and tantalum. The dotted lines are extrapolations of higher temperature measurements. 


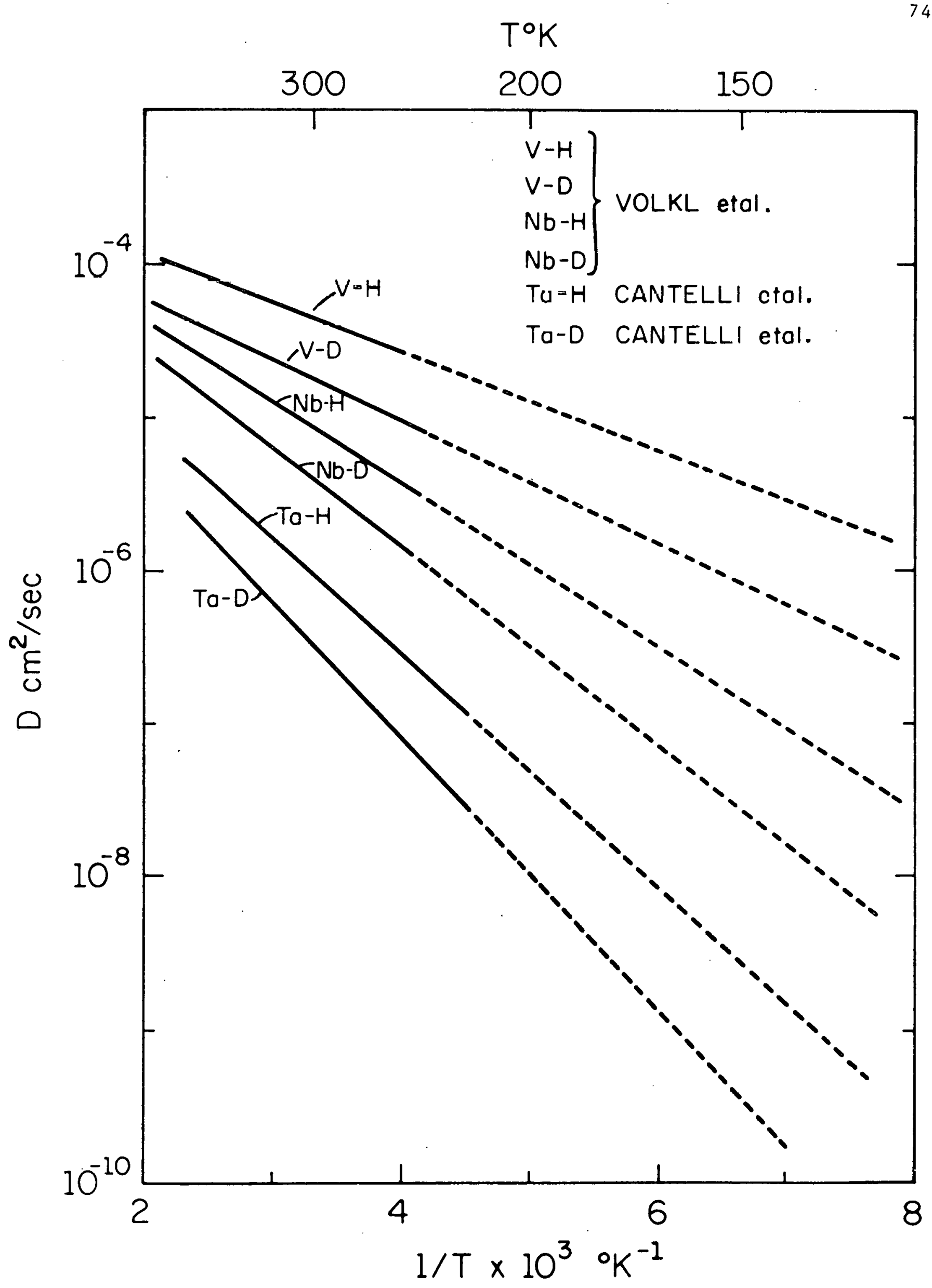


Figure 21. Increase in electrical resistivity as a function of hydrogen and deuterium in solid solution in tantalum. 


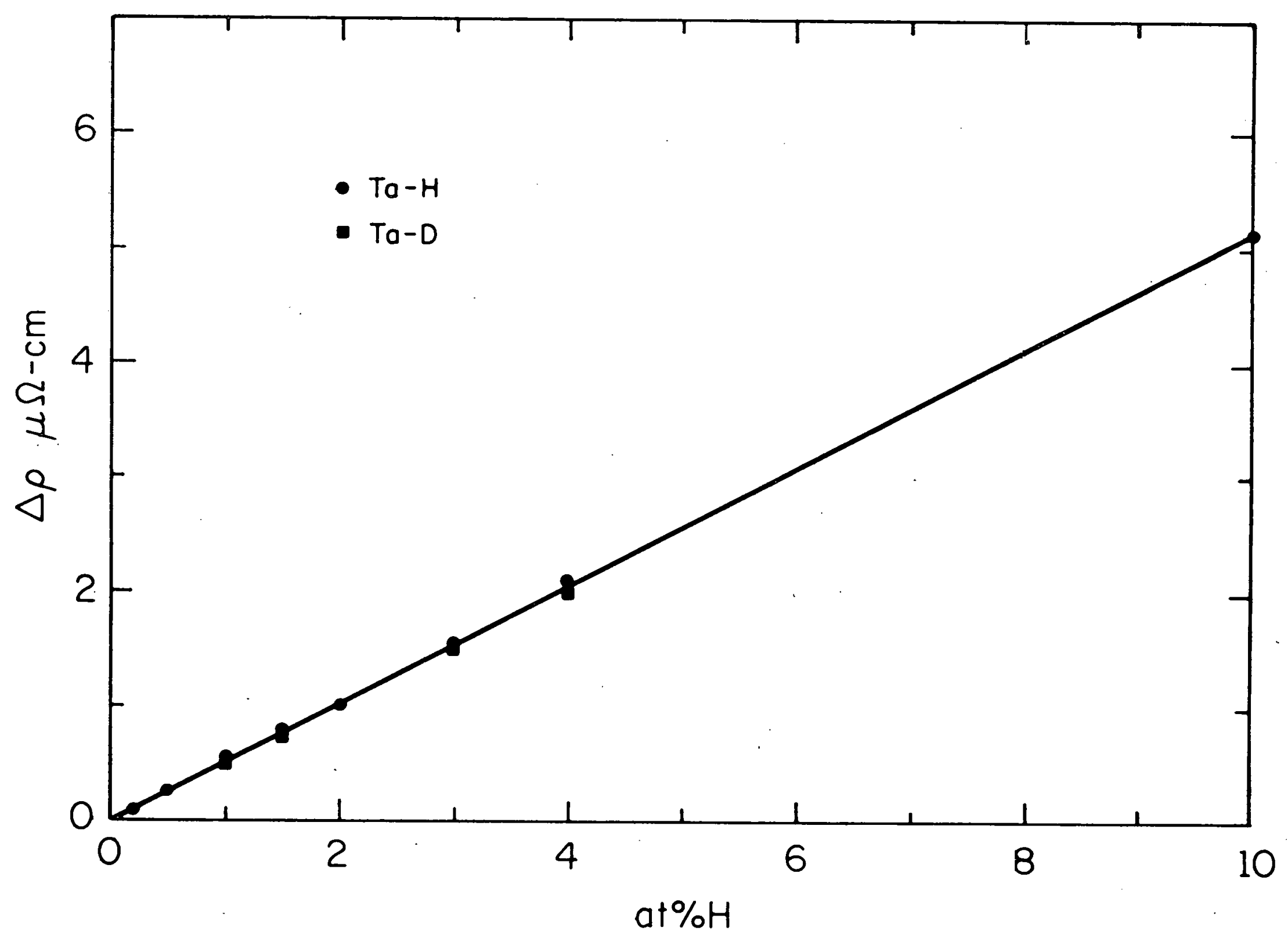


APPENDIX

For a single-phase solid solution of hydrogen and deuterium in tantalum, the resistivity of the alloy at any temperature is equal to the resistivity of the pure tantalum plus a constant $\Delta \rho$. This can be seen on a plot of $\Delta \rho v s$, temperature, see Figure 11。 $\Delta \rho$ is defined as

$$
\Delta \rho=\rho_{\mathrm{Ta}-\mathrm{H}^{-}} \rho_{\mathrm{Ta}}
$$

with $\rho_{\mathrm{Ta}-\mathrm{H}}$ and $\rho_{\mathrm{Ta}}$ being respectively the resistivity of the Ta-H alloy and that of pure Ta. Before precipitation of the hydride occurs $\Delta p$ is independent of the temperature. Thus hydrogen in solid solution contributes only to the residual resistivityd and not to the ideal resistivity.

This increase $\Delta \rho$ due to hydrogen and deuterium is plotted vs. concentration in Figure 21\% The resistivity increase is found to be $0.51 \mu \Omega$ cm per at.\%. This value is lower than for $\mathrm{V}-\mathrm{H}$ and $\mathrm{Nb}-\mathrm{H}$ alloys. For $\mathrm{Nb}-\mathrm{H}$ alloys Westlake ${ }^{16}$ reports a value of $0.655 \mu \Omega \mathrm{cm}$ per at.\% compared to $0.75 \mu \Omega \mathrm{cm}$ per at.\% found by Borgucci and Verdini。 30 For V-H alloys Westlake has found $\Delta \rho$ to be $1.12 \mu \Omega \mathrm{cm}$ per at $\% \%$ For Ta-H alloys Borgucci and Verdini report a value of $0.80 \mu \Omega$ em per at.\%. It can also be seen in Figure 21 that the contribution to the residual resistivity is identical for hydrogen and deuterium. This is not the case in. the vanadium systems where the value of $\Delta p$ is 
smaller than that due to hydrogen. In the V-D system $\Delta \rho$ is approximately $0.8 \mu \Omega \mathrm{cm}$ per at.\%。 22 


\section{LIST OF REFERENCES}

1. F. Ducastelle, R. Caudron and P.Costa, J. Phys Chem Sol. 31, 1247 (1970)。

2. T. Walte, W. Wallace and R。Craig, J.Chem. Phys. 24, 631 (1856).

3.K. Kel1ey, J。Chem。 Phys。名, 316 (1940).

4. G. Canne111 and F。 Gazzola1, Nuovo Cimento 64B, 171 (1969).

5. B. Pedersen, T. Krogdahl and O. Stokkeland, J.Chem。 Phys. 42, 72 (1965)。

6. C. Owen and To Scott, Met. Trans.3, 1715 (1972)。

7. T. Matsuyama, S. DohI and K. Hisano, Jap. J.AppI.Phys. 12, 609 (1973).

8. E. Veleckis and R. Edwards, J。Phys. Chem。 73, 683 (1969).

9. D. Westlake, Trans。AIME 239, 1341 (1967).

10. H. Chang, Ph. D. Thes1s, University of Illinols at UrbanaChampaign (1972).

11. H. Chang and C. Wert, Acta Met. 21, 1233 (1973).

12. G. Cannel11 and F。Mazzola1, J. Phys. Chem. Sol. 31, 1913 (1970)。

13. R. Waltex and W. Chandiex, Trans, AIME 233, 762 (1965)。

14. D.Thompson, C. Wert and O.Buck, J。Phys。Chem. So1. 31, 1793 (1970).

15. C. Baker and H. Birnbaum, Acta Met. 21, 865 (1973)。

16. D. Westlake, Trans, AIME 245, 287 (1969).

17. D. Westlake and S. Ockers. Submitted for publication.

18. G. Holmquist, M. S. Thesis, University of I1Inois at Urbana-Champaign (1973).

19. T. Schober, Scripta Met. I, 1119 (1973)。 
20. NoPaton, B. Hickman and D. Leslie, Met. Trans。2, 2891 (1971).

21. R. Oriani, Acta Met。 18, 147 (1970)。

22. D. Westlake and S。Ockers, Met.Trans.4, 1355 (1973).

23. G。Canne11i and F. Mazzolai, 7 th International Congress on Acoustics, Vol, 2. Akademia Kiodo, Budapest, 357 (1971).

24. R. Pryde and T. Tsong, Trans. Faraday Soc。65, 297 (1969).

25.G。Canne11i and R. Cante11i. Unpublished.

26. W. Saba, W。 Wallace, Ho Sandmo and R。Craig, J. Chem。 Phys. $\underline{35}, 2148$ (1961).

27. R. Cantel1i, F。 Mazzolai and M。Nuovo。 Unpublished。

28. R。 Cante11i, F。 Mazzolai and M。 Nuovo, J. Physique $\underline{32}$, C2-59 (1971).

29. J.Vök1, G。Schaumann and G。Alefeld, J。Phys. Chem.Sol. 31, 1805 (1970).

30. M. Borgucci and L. Verdini, Phys. Stat. Sol。 9,243 (1965). 
VITA

Philippe Lecocq was born June 2, 1948 in Brugge, Belgium。After a special admission test, he entered the University of Tilege in October, 1964 and received the degree of "Ingenieur Physicien" in July, 1969. He entered the Graduate College of the University of Illinois in UrbanaChampaign in september, 1969 and held a research assistantship. He is a member of ASM and AIME. 
